\title{
Redes sociales y correspondencia epistolar. Del análisis cualitativo de las relaciones personales a la reconstrucción de redes egocentradas ${ }^{1}$
}

\author{
José María Imízcoz Beunza²- Universidad del País Vasco, España \\ Lara Arroyo Ruiz- Universidad del País Vasco, España
}

\begin{abstract}
Resumen
En Historia, la correspondencia epistolar privada, en cuanto medio de comunicación entre personas, es la única fuente documental que revela las interacciones directas, no mediatizadas institucionalmente, entre actores sociales. El artículo explora las posibilidades de esta fuente tanto para el análisis cualitativo e intensivo de las relaciones personales como para reconstruir la "red egocentrada" del receptor de las cartas y llevar a cabo un análisis efectivo de redes sociales, aplicando los métodos y parámetros del "Social Network Analysis". A partir de dos ejemplos centrados en epistolarios del siglo XVIII, los autores muestran las posibilidades y limitaciones de los análisis cualitativos clásicos y el interés de las aportaciones específicas del análisis de redes egocentradas, abogando por la combinación de ambas metodologías.
\end{abstract}

Palabras clave: Correspondencia epistolar, relaciones personales, redes egocentradas, análisis de redes sociales, lazos fuertes, lazos débiles, densidad, globalidad, XVIII, imperio, corte, provincia, España, América.

\begin{abstract}
Historically speaking, private correspondence as a means of direct communication between people provides unique source documents that reveals direct, institutionally unmediated interactions among social actors. This article explores the potential of such a source for both qualitative analysis and intensive personal relations in order to reconstruct the "ego-centered network" of letters received, and carry out effective analysis of social networks, using "Social Network Analysis" methodology. Two such examples focus on eighteenth-century epistolary, the authors show the possibilities and limitations of classical qualitative analysis and the import of specific contributions regarding ego-centered network analysis; they advocate the combination of both methods.
\end{abstract}

Key words: Correspondence, relationships, ego-centered networks, social network analysis, strong ties, weak ties, density, comprehensiveness, XVIII, Empire, Court, Province, Spain, America.

\footnotetext{
${ }^{1}$ Proyecto de investigación del Ministerio de Ciencia e Innovación HAR2010-21325-C05-02, sobre "Las élites de la modernidad: Familias, redes y cambio social, de las comunidades tradicionales a la revolución liberal, 1600-1850", dirigido por José María Imízcoz, en el marco del Proyecto Coordinado HAR2010-21325-C05, años 2011-2013.

2 Enviar correspondencia a josemaria.imizcoz@ehu.es
} 
REDES- Revista hispana para el análisis de redes sociales

Vol. 21, \#4 Diciembre 2011

http://revista-redes.rediris.es

Desde hace tiempo venimos reflexionando sobre vínculos personales y redes sociales, propugnando, en la investigación histórica, un "análisis relacional" que parta de los actores sociales y de sus interacciones para reconstruir sus configuraciones efectivas y explicar mejor, por esta vía, su agencia histórica y los procesos de cambio que construyen con su acción (Erickson 1997, Lemercier 2005, Imízcoz 2011b). El análisis relacional ha tenido diversas aplicaciones en historia, desde el trabajo cualitativo clásico sobre los lazos personales hasta las más recientes reconstrucciones de redes, siguiendo el "Social Network Analysis" o "análisis de redes sociales" establecido por la sociología de redes (Imízcoz 2009). En este texto vamos a explorar las posibilidades que ofrece a los historiadores la correspondencia epistolar como fuente documental, tanto para el análisis cualitativo de las relaciones personales como para reconstruir redes "egocentradas", es decir, el conjunto de relaciones de un individuo que revela su correspondencia.

Pero, antes que nada, conviene aclarar conceptos, dada la polisemia y confusión extrema con que los historiadores están utilizando el término de "red social". En el primer y más tradicional enfoque, el del análisis cualitativo de las relaciones personales, se suele utilizar el término de "red" de forma metafórica, para referirse a una serie compleja de interrelaciones dentro de un sistema social. Este uso es, sin duda, insuficiente, como se encargan de recordar los especialistas de la sociología de redes, aunque, desde nuestro punto de vista, no deja de ser útil mientras se utilice correctamente, evitando una concepción naturalista muy extendida que tiende a ver una red como una cosa, como una formación social definida. En el extremo de esta concepción se utiliza red como sinónimo de grupo, se reifica y se le atribuye agencia histórica: la red se extiende, conquista espacios de poder, actúa en el mercado, desplaza a competidores, etc. En una versión más blanda, a esta visión obedecen también las propuestas frecuentes que definen la red como una "red de solidaridad" en que una serie de personas tienen habitualmente relaciones estrechas de ayuda y reciprocidad entre sí. En Historia, uno de los trasvases más fuertes hacia el estudio de redes sociales se ha producido desde un sector de la "historia de la familia" que, abandonando la vieja demografía histórica, ha aprovechado su experiencia sobre matrimonios, padrinos de bautismo, parentesco, etc. para pasar a hablar de "redes sociales" (Annales de Démographie Historique, "Histoire de la famille et analyse de réseaux", n¹, 2005; Lemercier 2005, Bertrand 1999, González Gómez y Basaldúa Hernández 2007). Muchas veces, sin embargo, más que de un verdadero análisis de redes, se trata del estudio en un plano de las relaciones familiares y de parentesco, muy alejado de la percepción poliédrica que permite, como veremos, un efectivo análisis de redes. 
REDES- Revista hispana para el análisis de redes sociales

Vol. 21, \#4 Diciembre 2011

http://revista-redes.rediris.es

En este tipo de planteamientos, el concepto y los contenidos de la red están más o menos predefinidos y se limitan, en realidad, a una parte de lo que los "análisis de redes" entienden por "red social", esto es, solamente a la parte más densa y evidente de una red de relaciones. Estas formas de hablar son útiles y operativas para el historiador a la hora de articular sus discursos, pero poco aportan al proyecto investigador de los análisis de redes de intentar observar las redes de relaciones en toda su amplitud y complejidad.

Esta metodología plantea la cuestión al revés. No parte de una definición a priori, plana o cerrada, de lo que es "red social". Entiende una red como un conjunto de conexiones entre actores relacionados de un modo $u$ otro a través de interacciones efectivas que se producen en un momento dado. En el fondo, se trata de observar, de la manera más completa posible, el conjunto de interacciones entre individuos para detectar las formas de articulación que estas revelan, desde los grupos o "cliques" de personas más vinculadas entre sí hasta las relaciones más ocasionales o alejadas de esos entornos densos. Con respecto a otros usos metafóricos o aproximativos, los específicos "análisis de redes sociales" han establecido herramientas analíticas que permiten reconstruir efectivamente el conjunto de relaciones entre actores, medir, a través de diversos parámetros, las características de su conectividad y representarlas gráficamente en forma de red (Wasserman y Faust 1994, Degenne y Forsé 1994, Carrington, Scott y Wasserman 2005, Requena 2003).

Una de las objeciones de los historiadores profanos con respecto a la posibilidad de aplicar los "análisis de redes sociales" a la Historia es la falta de fuentes documentales adecuadas para percibir con suficiente amplitud y complejidad las redes de relaciones de los individuos. De un modo general, la disponibilidad de fuentes es un problema tradicional de los historiadores y en este caso lo es especialmente, al menos con respecto a las enormes posibilidades de información que manejan los análisis de redes de la sociología contemporánea. Sin embargo, entre las fuentes históricas que reflejan las interacciones entre los individuos, la correspondencia epistolar es una documentación de primera magnitud, con un gran potencial, que ha sido muy poco empleada hasta ahora, al menos en el sentido que aquí planteamos. Por ello, nos parece útil centrar este artículo en una reflexión epistémica y metodológica, a partir de nuestra experiencia investigadora, sobre la correspondencia privada y sus posibilidades para el análisis de redes sociales. 
REDES- Revista hispana para el análisis de redes sociales

Vol. 21, \#4 Diciembre 2011

http://revista-redes.rediris.es

En un primer momento presentaremos la correspondencia como fuente para el estudio de las interacciones personales. En un segundo momento, mostraremos las posibilidades del análisis cualitativo de las relaciones personales a partir de epistolarios. En un tercer tiempo, pasaremos del análisis cualitativo al "análisis de redes sociales", centrándonos en los métodos de trabajo para reconstruir redes egocentradas a partir de dicha fuente y pondremos en valor algunos parámetros del "Network Analysis" que, por esta vía, se pueden aplicar en la investigación histórica. Para terminar, cerraremos con una reflexión sobre las aportaciones específicas de la reconstrucción de redes egocentradas a la historia.

\section{La correspondencia epistolar y los análisis de redes sociales}

La disponibilidad de fuentes documentales condiciona las posibilidades del historiador. Aquí también los grupos de las élites son privilegiados. Los historiadores han percibido las relaciones personales entre actores a través de fuentes muy diversas. Algunas de ellas son clásicas. Recordemos la utilización de los registros parroquiales para identificar a los padrinos de bautismo. O el empleo de las actas notariales, como testamentos, capitulaciones matrimoniales, poderes, escrituras de compra-venta, permutas, arrendamientos, etc., para reconstruir la vida económica y social de las familias y sus intercambios con el entorno (Por ejemplo, Gourdon, Beauvalet y Ruggiu 2004). O la documentación judicial -civil y eclesiástica-, que procura abundantes testimonios sobre las vinculaciones y las enemistades de las partes en litigio. Por su parte, los documentos autobiográficos, como diarios y memorias, permiten acercamientos cualitativos de gran intensidad a las relaciones de algunos individuos. Sin embargo, la correspondencia epistolar privada, como medio de comunicación entre personas, es la única fuente documental que revela interacciones directas -no mediatizadas institucionalmenteentre actores sociales.

En los últimos años se está abriendo camino la utilización de la correspondencia para el estudio de las relaciones interpersonales y de las redes sociales, con un uso intensivo, muy alejado de la ejemplificación episódica tradicional (Beaurepaire 2002, Beaurepaire y Taurisson 2003, Beaurepaire y Häseler 2006, Bergamasco y Bossis 2007). La correspondencia constituye una fuente de primera magnitud para la investigación de las redes sociales de las élites. Aporta información privilegiada tanto para reconstruir la "red egocentrada" de un personaje como para llevar a cabo un trabajo cualitativo sobre los contenidos de las relaciones entre actores sociales: sobre lo que se intercambia y circula a través de ellas (favores, información, ideas, recursos materiales, influencia...), sobre las funciones y 
REDES- Revista hispana para el análisis de redes sociales

Vol. 21, \#4 Diciembre 2011

http://revista-redes.rediris.es

atributos de cada vínculo, sobre los valores e ideas con los que los individuos actúan y se relacionan entre sí, o sobre la evolución de sus relaciones en el tiempo (Imízcoz y Caula 2004).

Se suele alegar que la correspondencia es una fuente escasa, pero en el caso de las élites no es cierto. Se conservan no pocos epistolarios de gobernantes, nobles, comerciantes, eclesiásticos y hombres de letras, tanto en archivos privados como en archivos públicos. Otra cosa es que se hayan trabajado poco y superficialmente. La evolución historiográfica no ha favorecido, hasta ahora, a esta fuente. En una época en que los enfoques dominantes priorizaban las "bases" demográficas y económicas, las clases sociales, las estructuras mentales y las fuentes cuantitativas y seriales, la correspondencia epistolar podía parecer anecdótica. En las últimas décadas, con la vuelta a un primer plano del sujeto como actor de historia y, por lo tanto, como punto de partida para la escritura de una historia a partir de los actores y de sus configuraciones colectivas efectivas, la correspondencia se descubre como una gran oportunidad.

En los últimos años han proliferado los trabajos y grupos de investigación que, desde diversos enfoques, trabajan sobre correspondencia epistolar (Sáez y Castillo 2002, Mestre 1999-2000, Testón y Sánchez Rubio 2008, Lorenzo Cadarso 2001), estudian epistolarios familiares (Antón Pelayo 2005) y extienden la utilización de esta fuente documental cada vez a más campos, como la historia de las mujeres (Díaz y Siess 2006, García Mouton 1996-1997) o la historia de la Ilustración (Urkia y Risco 2005).

Pero el trabajo sistemático con la correspondencia no es sencillo ni de rentabilidad inmediata. Requiere tiempo y una metodología específica. Nuestro planteamiento se centra en una explotación intensiva de la correspondencia y, en este sentido, dista mucho de algunos usos de esta fuente relativamente frecuentes en el pasado. A menudo se ha hecho un empleo superficial o episódico de las cartas. Por ejemplo, para ilustrar aspectos de la vida familiar o de la vida cotidiana, o para dar viveza al discurso, mediante citas hábilmente seleccionadas. También se han utilizado las expresiones de parentesco, amistad o patronazgo que emplean los corresponsales para ilustrar una percepción meramente formal de sus relaciones. En ocasiones se han utilizado cartas sueltas, como las misivas de emigrantes enviadas desde Indias que se encuentran insertas, por ejemplo, como pruebas documentales en determinados legajos judiciales (Usunáriz 1992). Estas cartas sueltas no dejan de tener interés, pero, por muy abundantes que resulten, no sirven para lo que aquí se propone. En disciplinas como la Literatura o la Historia del Arte ha sido tradicional 
REDES- Revista hispana para el análisis de redes sociales

Vol. 21, \#4 Diciembre 2011

http://revista-redes.rediris.es

trabajar sobre la correspondencia entre dos personajes, y esto ha tenido algunas aplicaciones en Historia. Sin embargo, este enfoque no sirve para el análisis de redes sociales, ya que para este se requiere, por definición, la correspondencia de un individuo con el conjunto de sus corresponsales, no solamente con uno de ellos. Esta tradición de la Literatura y el Arte podría llevar a los archiveros a clasificar las cartas de un epistolario por corresponsales, en lugar de preservar el orden cronológico natural en que se han ido produciendo. Esto rompería la unidad histórica del corpus documental y dificultaría notablemente el trabajo del historiador a la hora de intentar reconstruir esa unidad, dado que es imposible conocer a priori todos los individuos que participan e interaccionan en torno a un mismo asunto.

Como ocurre con cualquier fuente documental, el historiador tiene que evaluar el estado de conservación de las cartas con las que trabaja, sobre todo si pretende llevar a cabo un trabajo de reconstrucción de redes sociales. A veces se alega que las cartas se tiran o se expurgan. El trabajo intensivo con las cartas permite evaluar el grado de conservación de las mismas, en la medida en que los corresponsales suelen encabezar sus misivas refiriéndose a la carta anterior que han recibido, a la que responden. La continuidad de los asuntos, las referencias a cartas de otros corresponsales o las noticias cruzadas son elementos contextuales que ayudan a percibir el grado de conservación o las carencias en diferentes momentos de una correspondencia.

Un epistolario bien conservado nos ofrece una percepción muy rica de la red de relaciones del destinatario de las misivas. Con una salvedad muy importante que hay que tener en cuenta. La correspondencia sólo refleja la parte de la red con la que un individuo se relaciona a través de cartas, ya sea directamente (los corresponsales) o indirectamente (las referencias de los corresponsales a personas con las que estos se hallan a su vez relacionados) Por lo tanto, su principal carencia es que no recoge las relaciones de aquellos que, por su proximidad geográfica, no se escriben, aunque algunas de estas relaciones aparezcan reflejadas indirectamente, a través de referencias, en las cartas. Para conocer los lazos del entorno inmediato es necesario recurrir a las fuentes clásicas, notariales, judiciales, parroquiales, municipales, familiares y autobiográficas que habitualmente manejamos los historiadores (como hizo, de forma intensiva y nominativa, Levi 1990). 
REDES- Revista hispana para el análisis de redes sociales

Vol. 21, \#4 Diciembre 2011

http://revista-redes.rediris.es

En cambio, la correspondencia epistolar es insustituible para conocer las relaciones que articulan las redes sociales más allá del círculo local. No en vano el uso sistemático de las cartas se inició y se ha desarrollado especialmente en los trabajos sobre la emigración (en el ámbito hispánico, por ejemplo, Sánchez Rubio y Testón 1999, Márquez 1988 y 2004-2005) y sobre las relaciones mercantiles (en el comercio colonial hispanoamericano, por ejemplo, Caula 2000, Hausberger 2003, Arroyo 2007, Lamikiz 2007). Además de esto, la correspondencia epistolar resulta especialmente útil para acercarse a fenómenos como las redes de poder en la monarquía, el gobierno de los territorios, las relaciones entre la corte, las provincias y el imperio, las conexiones entre el privilegio político y la economía de los grupos dirigentes, o las redes religiosas, intelectuales y políticas. De hecho, el uso intensivo de la correspondencia se desarrolla a medida que la historiografía empieza a superar la historia local y regional más enclavada geográficamente para buscar una "historia conectada" o "transnacional". Una virtualidad con respecto a la historia localista es que permite conectar lo local con los centros de poder y riqueza y con los fenómenos de circulación diferencial de recursos, ideas y valores (Pourchasse y Beaurepaire 2010) que tanta incidencia pueden tener en la propia historia local, contribuyendo a explicar mejor los fenómenos de producción y difusión del cambio histórico.

Por otro lado, un epistolario contiene, normalmente, las misivas que recibe el destinatario de las cartas, pero no las suyas propias. El trabajo se enriquece cuando se conservan, además, los copiadores de cartas en que determinados personajes consignaban los borradores de las misivas que enviaban. Esta práctica no era inhabitual, por ejemplo, entre los grandes mercaderes, como muestran, por ejemplo, algunos epistolarios de comerciantes coloniales con América.

El trabajo intensivo con la correspondencia es lento. Empieza con la identificación nominal de los individuos y de sus relaciones, tanto de los corresponsales directos, autores de las cartas, como de todas las personas relacionadas con ellos a las que mencionan en sus misivas: quiénes son, qué son unos con respecto a otros, qué relaciones mantienen entre si, en qué asuntos o negocios participan, qué recursos, favores e informaciones intercambian, etc. Esta identificación no es fácil. Una carta no es un acta notarial o un proceso judicial en que un escribano consigna todas estas cosas con claridad. Muchas veces, la complicidad entre los corresponsales hace que no necesiten explicitarlas, puesto que saben de quién y de qué hablan. Generalmente, la única manera de comprender y completar la información es seguir el curso de la correspondencia para identificar, desde el comienzo de un asunto, de qué se trata y quiénes participan en él. Además, el trabajo de identificación 
REDES- Revista hispana para el análisis de redes sociales

Vol. 21, \#4 Diciembre 2011

http://revista-redes.rediris.es

requiere cruzar las referencias de las cartas con otras fuentes que informan sobre la familia y sus allegados, como genealogías, libros parroquiales, actas notariales o libros de cuentas.

Una última reflexión en este sentido. La correspondencia no es una fuente aislada y, como cualquier documentación, se debe trabajar combinada con otras fuentes. Esto nos remite a cosas muy sabidas, como la necesidad de cruzar las fuentes, o de combinar las escalas de observación. A esta idea general, la correspondencia añade un elemento específico. Las cartas se producen, generalmente, a medida que se desarrolla una acción y que diferentes individuos se implican en ella, se consultan, se conciertan, actúan y movilizan a otros para que actúen. Estas acciones, a su vez, generan otros documentos, papeles de muy diversa índole que se pueden redactar en instituciones y lugares muy variados, difíciles de adivinar a priori: actas notariales ante diferentes escribanos, informes varios, cuentas, pleitos en diversos tribunales. Las cartas informan a menudo sobre la producción de estos documentos, sobre la fecha, el agente, el lugar, la institución y la materia de que se trata, de modo que se pueden localizar en los respectivos archivos. En este sentido, la correspondencia ofrece un valioso hilo de Ariadna para agrupar y cruzar las fuentes directamente pertinentes que los actores interconectados producen con su acción.

Dentro de un tratamiento intensivo, la correspondencia se puede trabajar de diversos modos, según los objetivos del historiador, desde un trabajo más cualitativo, atento a observar los contenidos de las relaciones personales, hasta una reconstrucción de la red egocentrada del receptor de las cartas. Vaya por delante que, para nosotros, la combinación de ambos enfoques es sin duda la que procura mayor riqueza de análisis. A continuación, vamos a intentar ilustrar ambas formas de trabajo.

\section{La correspondencia epistolar para el análisis cualitativo de las relaciones personales}

Nuestra experiencia común proviene del trabajo con dos epistolarios del siglo XVIII, la correspondencia de Pedro José Gastón de Iriarte y la correspondencia de Juan Vicente de Marticorena. Aunque con diferencias de matices, ambos epistolarios corresponden a grupos familiares originarios del norte hidalgo de España, en este caso navarros, que, en el siglo XVIII, prosperaron simultáneamente en la Corte, la Alta administración, el Ejército, la Iglesia, los negocios en torno a la corona y el comercio colonial (Imízcoz y Guerrero 2004, Imízcoz 2008, Guerrero 2012). No entramos ahora a valorar las diferencias sociales de ambas parentelas. En lo que 
REDES- Revista hispana para el análisis de redes sociales

Vol. 21, \#4 Diciembre 2011

http://revista-redes.rediris.es

aquí nos ocupa, los miembros de estos grupos se caracterizan por una gran movilidad geográfica y social. Se hallan establecidos "a escala de imperio", en muy diversos lugares de España y de América, aunque muy conectados entre sí a través de cartas, y escapan a los marcos socio-profesionales clásicos, en la medida en que los individuos de estos grupos se hallan en procesos de movilidad social acelerada y tienen, por tanto, estatus sociales muy diversos que pueden ir desde campesinos y comerciantes hasta financieros de la corona, ministros, generales y obispos. Afortunadamente para nosotros, los individuos de estas redes "a escala de imperio" comunican intensamente entre sí y con sus relaciones a través de cartas. Esto permite observar la polivalencia de sus dinámicas, una polivalencia que en la historiografía sectorial clásica queda oculta por los habituales cortes geográficos y socio-profesionales. Su correspondencia revela la variedad de geografías, carreras y negocios en que se mueven; los cambios que experimentan en sus trayectorias, a lo largo de varias décadas, y los contenidos de las relaciones que establecen entre ellos y con individuos de otros segmentos sociales y de muy diversos territorios (Imízcoz y Oliveri, 2010).

Pedro José Gastón de Iriarte y Elizacoechea (Errazu, 1718-1789) es un notable local, dueño, entre 1755 y 1789, de la casa Iriartea del lugar de Errazu, una aldea del Valle de Baztán, situada en el Noroeste de Navarra. Pertenece a una familia de origen campesino que, a través de su parentesco con el financiero Juan de Goyeneche, se introduce desde finales del siglo XVII en los negocios de la Corte y coloca a sus hijos en cargos en la alta Administración, la jefatura del Ejército y el alto clero a lo largo de todo el siglo XVIII. En este movimiento, Pedro José Gastón de Iriarte fue llevado a la Corte con diez años, hizo carrera en las Guardias Reales, se retiró en 1755, con el grado de teniente coronel y la cruz de Santiago en el pecho, y sucedió como heredero en su casa nativa, donde recibió más de 700 cartas hasta su muerte, en $1789^{3}$. Dada la posición del receptor y las características de muchos de sus corresponsales, esta correspondencia es especialmente útil para percibir los flujos entre diversas instancias de la Monarquía y la comunidad local: la economía de vasos comunicantes entre territorios geográficamente alejados, como el Valle de Baztán, la Corte, Cádiz y diversas ciudades de España y de América, con todo lo que circula a través de estas relaciones epistolares. Una economía en la que Pedro José Gastón de Iriarte jugó un papel destacado como mediador entre los flujos de la Monarquía y la comunidad local (De Federico 2004, Ferrand 2002) ${ }^{4}$.

\footnotetext{
${ }^{3}$ Correspondencia conservada en el Archivo de la Casa Gastón de Iriarte, Valle de Baztan.

${ }^{4}$ Una reflexión sobre la dualidad local/no local de las redes sociales, sobre los lazos "puente" y los tipos de "cliques" que estos conectan, sobre la combinación de redes "locales" y "no locales, y los modos de
} 
REDES- Revista hispana para el análisis de redes sociales

Vol. 21, \#4 Diciembre 2011

http://revista-redes.rediris.es

La información que aporta una correspondencia como esta, sobre las relaciones entre actores, es de gran riqueza cualitativa. Muestra cómo funcionan realmente en la práctica: interacciones efectivas, no "relaciones nominales". Revela la pluralidad de sus dimensiones, sus solidaridades, tensiones, negociaciones y conflictos. Las relaciones aparecen con sus contenidos y atributos. Se evidencian los roles y funciones que juegan los diversos actores. Se observa el capital relacional y su uso, las funciones de mediación, el desarrollo de la acción, la movilización de los actores implicados en ella, la transmisión de la información, los intercambios de bienes y servicios, la circulación de favores, el poder de influencia efectivo, las conexiones con las instituciones, etc. Las cartas revelan también el significado que los propios actores dan a sus relaciones, su "economía moral". Expresan los valores, normas o ideas con las que éstos actúan y se relacionan entre si (Imízcoz 2003).

Así mismo, la secuencia cronológica de la correspondencia permite observar algo que los análisis de redes sociales tradicionales no suelen percibir y que es central para el historiador, la duración. Una correspondencia sostenida durante varias décadas revela la evolución de las relaciones en el tiempo, sus regularidades y sus variaciones, su renovación y su caducidad. Así, la observación cualitativa de las interacciones en la red de Pedro José Gastón de Iriarte, durante casi medio siglo, muestra la evolución de las relaciones personales a lo largo del tiempo y el significado de esta evolución para la construcción de economías compartidas y de dinámicas duraderas, o, al contrario, para la disolución y ruptura de los vínculos sociales.

La información de la correspondencia epistolar sobre los asuntos en que los actores se hallan implicados revela en su máxima amplitud documental la pluralidad de contenidos de estas relaciones, así como las dinámicas individuales y colectivas de los grupos de actores relacionados. Esto es, asocia, en la acción real, las redes de relaciones con la pluralidad de dimensiones en que los actores se mueven y con los procesos históricos en los que participan: sentimientos, ideas, economías, circulación, relaciones de poder, conflictos y solidaridades, universos culturales e ideológicos, construcciones socio-políticas, etc. Todos estos elementos tienen un valor inestimable para observar desde dentro la agencia histórica de los actores sociales, para percibir la conexión entre esferas de actuación que muchas veces observamos por separado y para explicar cómo se construyen, en la práctica, dinámicas históricas de reproducción y de cambio.

integración relacional de los migrantes -actores simultáneamente locales y no locales-, en De Federico 2004. 
REDES- Revista hispana para el análisis de redes sociales

Vol. 21, \#4 Diciembre 2011

http://revista-redes.rediris.es

En otras publicaciones hemos ejemplificado algunas posibilidades que ofrece el análisis cualitativo de esta información epistolar, de modo que no es necesario repetirlo aquí. Cabe, sin embargo, recordar algunas aplicaciones, remitiendo a ellas. Por ejemplo, a partir del epistolario de Pedro José Gastón de Iriarte, analizamos las cartas que se produjeron, entre septiembre de 1788 y marzo de 1789, con ocasión del intento de conseguir el ingreso de uno de sus hijos en la Academia de Artillería de Segovia, un cuerpo de élite muy selectivo en que 150 candidatos nobles pugnaban por conseguir una de las once plazas de cadetes disponibles aquel año (Imízcoz 2010a). En este caso, el análisis de la correspondencia muestra la diversidad de relaciones que la familia moviliza para conseguirlo, cómo los "lazos fuertes" de la parentela activan a sus amistades y a sus "lazos débiles", y permite desembocar en una reflexión sobre el "capital relacional" de las "élites estatales" en la España del siglo XVIII y sobre su significado diferencial en la formación de las redes de poder de la monarquía borbónica 5 .

Así mismo, las cartas enviadas desde la corte a Pedro José Gastón de Iriarte por su primo Juan Francisco de Lastiri, Secretario del Real Patronato de la Cámara de Castilla, nos informan sobre los intentos de estos y otros actores, en 1784, para conseguir financiación de la corona para el hospicio del lejano lugar de Elizondo, en el norte de Navarra. Este caso nos ha servido para mostrar cómo elementos de estas parentelas especialmente establecidas en la corte captaban información privilegiada sobre las posibilidades y recursos que se abrían a medida que se reforzaba el regalismo y se ampliaban las competencias del soberano, y cómo utilizaban sus amistades, relaciones profesionales y afinidades políticas con los ministros de la monarquía para intentar conseguir dichos recursos en favor de sus parentelas y comunidades (Imízcoz 2007). Este análisis nos llevaba también a reflexionar sobre cómo, en la nueva dinámica estatal de la segunda mitad del siglo XVIII, se estaban formando élites políticas de nuevo cuño, tanto en el centro -en la administración del estado ministerial- como en la periferia, íntimamente conectadas por sus intereses y redes sociales.

Las cartas que recibe Pedro José Gastón de Iriarte en torno a un pleito que mueve, en nombre de los vecinos del lugar de Errazu, ante el tribunal eclesiástico de Roma revelan cómo hay conflictos que, siendo locales, se dirimen, sin embargo, en otros lugares, en este caso en instancias de apelación. En esta ocasión, el conflicto opone a "los vecinos" de la aldea de Errazu (¿pero quienes están realmente detrás de este término corporativo?) con el patrono de la iglesia del lugar, por los nombramientos

\footnotetext{
${ }^{5}$ Un análisis de cómo la estructura de las redes sociales puede generar capital social y este producir beneficios tanto públicos como privados, en García-Valdecasas 2011.
} 
REDES- Revista hispana para el análisis de redes sociales

Vol. 21, \#4 Diciembre 2011

http://revista-redes.rediris.es

de los vicarios parroquiales, y es Pedro José Gastón de Iriarte, en nombre de dichos "vecinos" quien mueve el pleito. Se trata, aparentemente, de un conflicto clásico entre facciones de élites locales con sus respectivas clientelas, pero las cartas muestran cómo el líder de una facción local especialmente bien conectado, a través de sus relaciones personales, con otros espacios e instituciones de tutela mueve sus relaciones para conseguir sus propósitos. Este y otros ejemplos nos llevan a plantear la importancia de las redes sociales en la corte y en otros espacios de poder y riqueza no sólo para captar recursos fuera de la comunidad, sino para construir el poder de influencia en la propia comunidad (Imízcoz 2001).

El análisis cualitativo de las cartas, cruzado con otras fuentes, nos ha llevado también a analizar las relaciones internas en grupos de parentesco $y$, en este contexto, a plantear la cuestión de las "solidaridades vs. conflictos" y de "los márgenes de libertad de los individuos" con respecto a una definición normativa y ritualizada de los lazos personales (Imízcoz 1998). A partir de las interacciones efectivas reveladas por la correspondencia epistolar, pudimos aprehender los intereses de los individuos en el funcionamiento efectivo de una economía compartida en la que participan y de la que se benefician. Observando la evolución de estos lazos en el tiempo, pudimos constatar cómo las relaciones más efectivas por sus aportaciones a esa economía compartida tendían a ganar en centralidad e influencia en la red de relaciones, y a devenir duraderas, incluso a reproducirse generacionalmente de diversas maneras (Imízcoz 2010c), orientando más fuertemente la dirección del grupo, mientras que otras relaciones menos efectivas tendían a devenir marginales. En este entorno más o menos denso, el interés individual está muy relacionado con la inserción del individuo en una economía de intercambios en que los demás esperan de él determinadas actitudes y contrapartidas. Por supuesto, el individuo puede tomarse márgenes de libertad con respecto a estas expectativas, pero su comportamiento tiene consecuencias. En nuestro caso, el conflicto de un individuo con elementos del núcleo más denso y unido de la red lleva a su expulsión del grupo y a la privación de sus solidaridades, al tiempo que la viabilidad de este no se resiente, al seguir sostenido por los lazos centrales que lo alimentaban (Imízcoz 2010b).

Para concluir con estos ejemplos cualitativos, podemos observar, a través de las cartas, la movilización entre 1779 y 1782 de varios parientes, establecidos en Navarra y en la corte, para obtener del rey una renta eclesiástica para un joven de la parentela que se destinaba a la carrera sacerdotal. Este ejemplo muestra de nuevo las conexiones estrechas de determinadas redes entre los territorios periféricos y la corte del soberano, cómo interactúan parientes establecidos 
REDES- Revista hispana para el análisis de redes sociales

Vol. 21, \#4 Diciembre 2011

http://revista-redes.rediris.es

simultáneamente en diferentes espacios e instituciones y cómo los elementos cortesanos de estas parentelas movilizan a sus relaciones profesionales 0 ministeriales para obtener la gracia del rey. Como se trata de un caso que no requiere demasiada extensión, citaremos las cartas para ejemplificar el modo en que estas nos informan sobre las relaciones y tratos entre actores.

En este caso, los padres del joven José Isidro de Dolarea, preocupados por la colocación de su hijo, recurren, desde la remota aldea de Gaztelu, en el noroeste de Navarra, a un pariente poderoso establecido en la corte, el mismo Juan Francisco de Lastiri de quien hemos hablado, primo carnal de la madre del muchacho, que podía intentar conseguirle una renta eclesiástica gracias a sus relaciones en el entorno del soberano. Sin embargo, la cosa no era fácil. Para estimularle, los padres de José Isidro movilizaron a otros parientes para que intercedieran ante él. En el intercambio epistolar vemos cómo se dirigen a Juan Francisco de Lastiri no sólo los padres de José Isidro, sino otros parientes que hacen causa común con ellos, como Juan Agustín de Uztáriz, importante comerciante gaditano con Indias, pariente de los Dolarea, que en ese momento se hallaba en Madrid, o la propia hermana de Lastiri, María Josefa, a la que este "ama de corazón".

Sin embargo, a pesar de la buena disposición inicial, las cosas no se hacen solas. Fueron necesarias acciones, mediaciones, amistosas presiones (Imízcoz y García del Ser 2008). Por las cartas conservadas, el 13 de febrero de 1779 tenemos las primeras noticias del asunto, cuando Juan Agustín de Uztáriz responde desde Madrid a las instancias de su pariente Pedro José de Dolarea y Barreneche y le da cuenta de su labor de mediación ante Juan Francisco de Lastiri:

"El señor Lastiri es algo tibio para pedir y procuraré avivarle siempre que le vea, a fin de que se empeñe de veras con el Ilustrísimo Padre Confesor para que a nuestro Joseph Ysidro le conceda alguna renta eclesiástica para seguir sus estudios"

El tiempo pasa, sin embargo. Parece que entre tanto se han perdido cartas. La cosa es que, un año más tarde, los padres del muchacho volvían a insistir en su demanda, apremiando al primo Lastiri:

"Pariente y muy señor mío: De parte de esta su prima [y esposa] mía, suplico a vuestra merced, recomendándonos nuevamente a su auxilio, que, continuando con el favor que nos tiene prometido para solicitar algún beneficio simple para ordenarse este nuestro hijo Joseph Ysidro, que está ya apto para ello en sus estudios, que corre en el seminario conciliar de Pamplona y sin renta alguna, causándonos bastante peso, se sirva ahora que nos parece ocasión oportuna, con el motivo presente de haber dado a luz la

\footnotetext{
${ }^{6}$ Archivo de la Casa Gastón de Iriarte (ACGI), carta de Juan Agustín de Uztáriz (Madrid) a Pedro José de Dolarea y Barreneche (Gaztelu, Navarra), 13 de febrero de 1779.
} 
REDES- Revista hispana para el análisis de redes sociales

Vol. 21, \#4 Diciembre 2011

http://revista-redes.rediris.es

princesa nuestra señora un infante, de facilitarnos esta gracia mediante la interposición de su persona y méritos, en que afianzamos ver este desempeño verificado para nuestro alivio y consuelo cuanto antes le sea posible (... $)^{\prime \prime \prime}$.

Por su parte, Lastiri respondía a estas demandas y daba cuenta de sus intentos:

"Pariente, amigo y señor: Recibí su carta de vuestra merced de 24 del pasado en la que me recomienda nuevamente la solicitud de algún beneficio a favor de Joseph Ysidro. Puedo asegurar a vuestra merced con toda verdad que tengo formal sentimiento, viendo que los repetidos pasos que he dado para la colocación no han tenido ahora efecto. Últimamente tengo presentado un memorial, con muchas promesas de que se me servirá, pero a vista de lo que me ha pasado en otras ocasiones, no quiero consentir seré más feliz en ésta. Crea vuestra merced que deseo con todas veras verle con un pedazo de pan y que no desistiré hasta conseguirlo (... $)^{1 / 8}$.

Se ve que la propia hermana de Lastiri le escribe también y se lo recuerda, probablemente empujada por los parientes Dolarea. Y Juan Francisco le responde, asegurando que lo intenta y exponiendo las dificultades que encuentra:

"Querida hermana: (...) No te puedo ponderar las continuas diligencias que estoy practicando para el acomodo del sobrino Ysidro, pero como el confesor del Rey está indispuesto y no despacha nada, está detenido todo lo eclesiástico $(\ldots)^{\prime \prime \prime}$.

Finalmente, el 2 de febrero de 1782, Lastiri escribe a su hermana anunciándole la primicia de que el rey había concedido una media prestamera a José Isidro, dejándole que sea ella quien anuncie la noticia a sus padres ( $y$, quizás, capitalizar así cierto crédito ante sus parientes como la hermana del "conseguidor"):

"Mi querida hermana: Esta mañana me han avisado del Pardo reservadamente cómo al sobrino Joseph Ysidro de Dolarea le ha dado el Rey una media prestamera, qué valdrá de trescientos a cuatrocientos ducados, moneda de Castilla, que los podrá comer en la casa sin carga alguna. Esta gracia no se publicará hasta de hoy en ocho días, pero a mi se me ha confiado amistosamente, como que he sido el solicitador. Te aseguro que tengo el mayor gusto y quiero que seas tú quien avises a la prima Maria Pepa, a quien no escribo nada dejándote a ti la acción para que lo hagas. Recibe mis expresiones de parte de Manuela y de la prima Felicia y Dios guarde los muchos años que desea tu hermano que te ama de corazón, Juan Francisco ${ }^{\prime 10}$.

El caso es bastante elemental y se puede representar con un diagrama sencillo, como el que se muestra a continuación, que no tiene más valor que el de esquematizar las pocas relaciones que intervienen en este asunto.

\footnotetext{
7 ACGI, carta de Pedro José de Dolarea y Barreneche (Gaztelu, Navarra) a Juan Francisco de Lastiri y Gastón, 24 de marzo de 1780.

8 ACGI, carta de Juan Francisco de Lastiri y Gastón (Madrid) a Pedro José de Dolarea y Barreneche (Gaztelu), 12 de abril de 1780.

${ }^{9}$ ACGI, carta de Juan Francisco de Lastiri y Gastón (Madrid) a María Josefa de Lastiri y Gastón, 3 de mayo de 1781.

${ }^{10}$ ACGI, carta de Juan Francisco de Lastiri (Madrid) a María Josefa de Lastiri, 2 de febrero de 1782.
} 
REDES- Revista hispana para el análisis de redes sociales

Vol. 21, \#4 Diciembre 2011

http://revista-redes.rediris.es

Relaciones en la obtención de una media prestamera para José Isidro de Dolarea y Gastón, 1779-1782

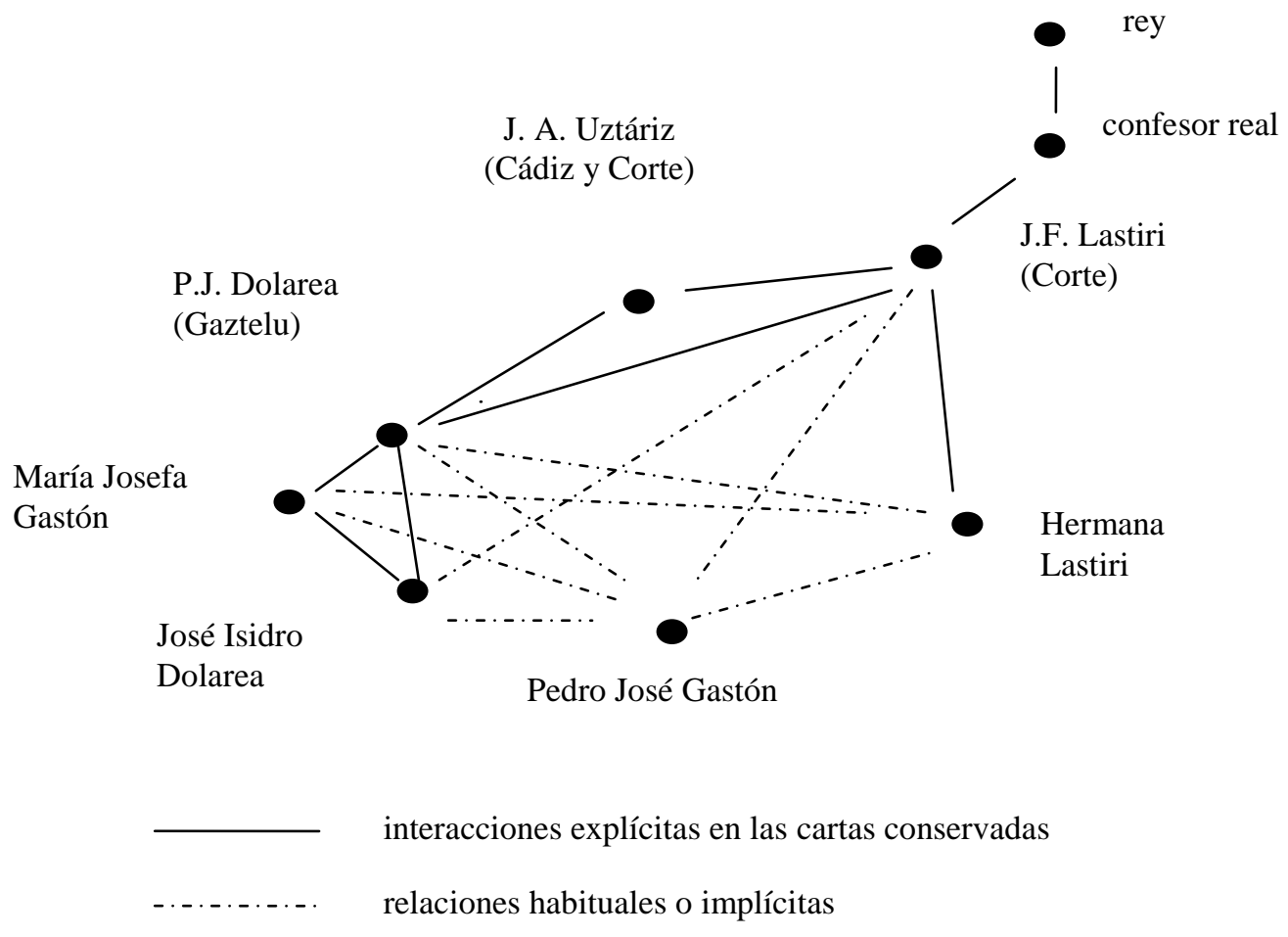

Figura 1. Relaciones en la obtención de una media prestamera para José Isidro de Dolarea y Gastón, 1779- 1782

Por el contexto de otras cartas que no están relacionadas con este asunto, observamos con qué otros parientes -que aquí no se citan, pero que ellos sabenestaban especialmente relacionados estos individuos, con quienes mantenía una economía de intercambios más intensa, cuyos servicios y contrapartidas -que aquí no se mencionan, pero que ellos conocen de sobra- eran necesarios si se quería mantener el crédito en esa economía de intercambios. En este caso, el favor se inscribe en las relaciones del núcleo denso de la red de Pedro José Gastón, especialmente en los intercambios de servicios continuados entre Juan Francisco de Lastiri, desde la Corte, y Pedro José Gastón de Iriarte, en Errazu, que se encarga, entre otras cosas, de la protección y administración de la casa nativa de Lastiri y del cuidado de sus sobrinas y, luego, de sus sobrinas-nietas. En estos intercambios participan otros parientes del círculo denso de relaciones de Pedro José, como los 
REDES- Revista hispana para el análisis de redes sociales

Vol. 21, \#4 Diciembre 2011

http://revista-redes.rediris.es

padres de José Isidro de Dolarea, María Josefa Gastón de Iriarte, hermana de Pedro José, y su marido Pedro José de Dolarea y Barreneche. Concretamente, en este caso, María Josefa Gastón de Iriarte había acogido en su casa a una sobrina-nieta de Lastiri, María Josefa de Landabere, al quedar esta huérfana de madre en 1779 (justamente cuando se inicia la demanda de una renta eclesiástica a Lastiri), y la cuidaría hasta su muerte en $1785^{11}$. Todo ello incidió seguramente en este asunto de la media prestamera y contribuye a explicar su resolución, aunque los actores no lo mencionen directamente en el intercambio epistolar específico que hemos citado. Esto muestra el interés de conocer el contexto relacional del conjunto de la red para sustentar un buen análisis cualitativo. Volveremos sobre ello a la hora de valorar las aportaciones de la perspectiva de redes egocentradas al análisis cualitativo

En estas observaciones cualitativas de la red de Pedro José Gastón de Iriarte hemos intentado aplicar a nuestro análisis conceptos puestos a punto por los "análisis de redes sociales", como el de "densidad" o el de "lazos fuertes y lazos débiles". Estos conceptos nos han sido útiles, pero con una utilidad limitada por una percepción más bien intuitiva e impresionista, al no haber reconstruido la red egocentrada ni medido realmente sus parámetros. En efecto, mediante un análisis intensivo de la correspondencia epistolar, podemos observar, en la red de Pedro José Gastón de Iriarte, un núcleo más denso de parientes y amigos que se conocen entre sí y cooperan activamente, alimentando unos intereses comunes y una economía más o menos compartida, y un conjunto muy variado de relaciones más ocasionales y periféricas. Algunos individuos se muestran especialmente implicados en la economía de sus parientes y amigos. Escriben con mayor frecuencia y regularidad, y sus cartas tramitan un intercambio intenso de favores, información privilegiada, servicios de mediación, movimientos de capitales, búsqueda de financiación, apadrinamientos directos y recomendaciones ante terceros. Estos individuos mueven parcelas importantes de la economía de su parentela, y de forma sostenida, durante décadas. En definitiva, estos "lazos fuertes" se nos presentan como el motor más central y constante de una economía compartida de la que se benefician una serie de "interesados". En otros trabajos hemos detallado los elementos de esta economía y, por lo tanto, no es necesario repetirlos aquí (Imízcoz 2010b).

${ }^{11}$ ACGI, Libro de cuentas de Pedro José Gastón de Iriarte, "Cuenta con don Juan Francisco de Lastiri", fols.165-170; carta de Juan Francisco de Lastiri (Madrid) a Pedro José Gastón de Iriarte, 17 de enero de 1784 y 14 de septiembre de 1784 . 
REDES- Revista hispana para el análisis de redes sociales

Vol. 21, \#4 Diciembre 2011

http://revista-redes.rediris.es

En este núcleo denso de la red, algunos individuos destacan especialmente como "conectores". A través de sus cartas cruzadas a unos y otros, los conectan especialmente entre sí, les implican en las necesidades de los suyos, movilizan a parientes y amigos, y promueven la cooperación y la concertación. De este modo, contribuyen a generar en la red núcleos densos con especial centralidad y capacidad de obtener resultados efectivos, a pesar de una separación geográfica superlativa.

Fuera de este entorno denso, los individuos establecen relaciones más abiertas y ocasionales, que conectan con espacios sociales más heterogéneos (Epstein 1969). Algunas de estas relaciones se establecían de forma más o menos duradera, pero en una única esfera compartida, como ocurría con las amistades estudiantiles, con las amistades militares o con las afinidades en las carreras administrativas y eclesiásticas. En estos casos se trataba, normalmente, de espacios separados de la esfera familiar, en que la familia podía seguir ejerciendo una influencia, pero esta tenía que compaginarse con las normas de otras esferas o instituciones. Otras relaciones, en cambio, eran ocasionales, podían resultar muy variadas y atravesar segmentos sociales e institucionales muy diversos (Moutoukias 2003b).

Estas partes alejadas de la red son difíciles de observar a simple vista, mediante el trabajo cualitativo clásico, y suelen escapar al historiador. Sin embargo, pueden jugar funciones importantes, como acceso a recursos o como apertura al cambio. Mark S. Granovetter ha distinguido, en una red social, los "lazos fuertes", aquellas relaciones del entorno más denso que conectan a los parientes cercanos y a los amigos íntimos que son amigos entre sí, de los "lazos débiles" que se establecen fuera de este entorno denso. "La fuerza de los lazos débiles" consiste en que, mientras los individuos conectados habitualmente entre sí tienen acceso a las mismas fuentes de información $y$ opiniones, $y$ a los mismos recursos y oportunidades, los "lazos débiles" abren el acceso del grupo hacia otros recursos, ideas y oportunidades (Granovetter 1973 y 1982; Moutoukias 2002).

Nuestras observaciones a partir de la correspondencia de Pedro José Gastón de Iriarte corrigen y completan los aspectos excesivamente estáticos del modelo de Granovetter. Dada la enorme movilidad geográfica y social de los grupos que estamos observando, los parientes y amigos de estas redes se hallaban establecidos simultáneamente en muy diversos lugares, administraciones y negocios, "a escala de imperio". Elevados en diferentes centros de poder y riqueza, como la corte, el mando del ejército, las catedrales del alto clero, el gobierno del imperio, las finanzas de la corona y el gran comercio colonial, sus carreras y 
REDES- Revista hispana para el análisis de redes sociales

Vol. 21, \#4 Diciembre 2011

http://revista-redes.rediris.es

empresas les daban acceso a múltiples fuentes de recursos y de oportunidades, que podían captar y distribuir abundantemente en su red de relaciones. De este modo, siendo "lazos fuertes", con relaciones densas entre sí a través de sus intercambios epistolares, jugaban, al mismo tiempo, el papel de "puentes" que Granovetter reserva a los "lazos débiles". Además, una ventaja añadida de estos vínculos, con respecto a los "lazos débiles" de Granovetter, es que se trataba de relaciones duraderas que procuraban, por tanto, no aportaciones ocasionales, sino sostenidas a lo largo del tiempo (Imízcoz 2010a, pp.268-273).

Pero, además, estos parientes establecidos en las instituciones de la monarquía y en los negocios podían movilizar numerosos lazos a favor de sus parientes: a sus amigos íntimos, a colegas de profesión, a sus amistades políticas, pero también a numerosas relaciones ocasionales o "lazos débiles". La correspondencia de Juan Francisco de Lastiri, por ejemplo, muestra la pluralidad de relaciones que este moviliza en la corte de Carlos III para obtener recursos para sus parientes y para su comunidad de origen: el ingreso de un sobrino en la Academia de Artillería (Antonio Angosto, el conde Lacy, "un sujeto de quien hace mucha estimación el conde de Lacy"...), la erección de nuevos beneficios patrimoniales en el Valle de Baztán (Manuel de Roda, Campomanes), la resolución de problemas de fronteras con Francia (el conde Fuentes, Ricardos, Ventura Caro), la obtención de una renta eclesiástica para un sobrino segundo (el confesor del rey), o la búsqueda de financiación para el hospicio de Elizondo (Pedro Joaquín de Murcia, Floridablanca, Ozta y Múzquiz, Arozarena, Iribarren, Sarratea). Este ejemplo ilustra especialmente la capacidad de estos "lazos fuertes", bien situados estratégicamente, para tejer amplias relaciones útiles y poder utilizarlas, en contextos muy competitivos, para conseguir recursos a los cuales, de otro modo, sus "interesados" no hubieran tenido acceso.

En definitiva, la utilización intensiva de la correspondencia epistolar para un análisis cualitativo de las relaciones personales tiene muchas virtualidades. Sin embargo, pronto encuentra sus limitaciones, cuando queremos tener una percepción más completa y segura de una red de relaciones más amplia, en la que intervienen simultáneamente decenas o centenares de personas, en asuntos muy diversos, en diferentes esferas de actuación y territorios, con una complejidad de análisis mucho mayor. Con respecto a la observación cualitativa de las relaciones de persona a persona, la reconstrucción y análisis de una red egocentrada aporta cosas importantes. Procura una percepción global y cuantificable del conjunto de actores que interactúan en un determinado momento y del conjunto de asuntos, esferas y territorios que están en juego. Permite calcular los parámetros de la conectividad 
REDES- Revista hispana para el análisis de redes sociales

Vol. 21, \#4 Diciembre 2011

http://revista-redes.rediris.es

de una red -por ejemplo, su densidad, centralidad vs. dispersión, o mediación- y, por lo tanto, posibilita comparar la estructura de diferentes redes sociales, en una historia que debería ser comparativa. Así mismo, permite representar gráficamente la estructura de la red y sus partes, un instrumento muy útil para analizar y comparar redes (De Grande y Eguía 2008).

Además de estas virtualidades propias, el análisis de redes puede contribuir a mejorar el análisis cualitativo mismo, al permitir ver cosas que de otro modo no veríamos, o no con tanta claridad. Por ejemplo, da mayor base y seguridad al análisis cualitativo de las interacciones, al situar mejor cada relación interpersonal en el contexto relacional efectivo en un momento dado, un conjunto de interacciones siempre mucho más amplio y complejo de lo que puede percibir a simple vista una mirada impresionista. La percepción más amplia y segura del conjunto de interacciones y de la pluralidad de sus contenidos permite entender mejor cómo las interacciones con terceras personas influyen en las relaciones interpersonales diádicas. O cómo se interconecta, en la práctica, a través de sus interacciones, la pluralidad de esferas en que los actores actúan: política-economíacultura, o provincia-corte-imperio, o negocios y privilegio político (Imízcoz y Guerrero 2011), etc. Desde nuestro punto de vista, el análisis cualitativo y el "network analysis" alcanzan sus mejores resultados cuando se complementan mutuamente.

El objeto de este artículo no es demostrar qué aportan los parámetros del "network analysis" con respecto a los análisis cualitativos, en la medida en que la sociología de redes ha producido una abundante bibliografía científica sobre ello. En cambio, sí nos parece útil para los historiadores mostrar cómo se puede proceder a la reconstrucción de redes egocentradas a partir de la correspondencia epistolar, siguiendo nuestra experiencia investigadora en este campo. 
REDES- Revista hispana para el análisis de redes sociales

Vol. 21, \#4 Diciembre 2011

http://revista-redes.rediris.es

\section{La reconstrucción de "redes egocentradas" a partir de la correspondencia epistolar}

Un epistolario bien conservado permite llevar a cabo una reconstrucción de la red egocentrada del receptor de las cartas -evidentemente, hasta donde la documentación alcance- y medir sus características, tanto las propiedades del conjunto como los rasgos de las diversas relaciones o grupos de relaciones dentro de la red. Vamos a comentar la forma de hacerlo a través de un ejemplo, para luego sacar algunas lecciones sobre el tipo de cosas que este procedimiento permite ver.

Lara Arroyo ha reconstruido la red egocentrada de Juan Vicente de Marticorena Laurnaga en 1793. La correspondencia epistolar de este "comerciante" se extiende de 1780 a 1809 y comprende más de 3000 cartas. Casi en su totalidad, se trata de cartas destinadas a Juan Vicente Marticorena, establecido en Cádiz como representante de la casa de comercio familiar de los Marticorena. Estos eran cuatro hermanos provenientes de la villa de Echalar, en el Noroeste de Navarra, que se asientan en Cádiz (Juan Vicente se inscribe en la matrícula de comerciantes gaditanos en 1776) y en las Indias: Juan Miguel en Lima, Juan Bautista en Guatemala y Miguel Jacinto en México. Originarios del mundo rural norteño, los hermanos Marticorena intentarán un proceso de ascenso social como el que habían seguido anteriormente varias generaciones de familias de orígenes semejantes, a través del enriquecimiento en el comercio colonial. Sin embargo, este proceso se verá truncado por el contexto adverso para el comercio atlántico, a comienzos del siglo XIX (Arroyo 2007 y 2010).

Concretamente, en el ejemplo que se observa a continuación, Lara Arroyo ha reconstruido la red egocentrada de Juan Vicente Marticorena en el primer semestre de 1793, a partir de las misivas que recibe en estos seis meses ${ }^{12}$. Se trata de 115 cartas de 37 corresponsales, que escriben desde muy diversos lugares de España y América, en las que se hace referencia a un total de 201 personas. El diagrama $\mathrm{n}^{0} 1$ representa la estructura de la red que revelan estas cartas. Recoge el conjunto de las interacciones directas o indirectas que mantiene este individuo en ese momento, tal y como se reflejan en su correspondencia.

\footnotetext{
12 Siguiendo la vía abierta en Historia por Zacarías Moutoukias (2003c), quien reconstruye la red egocentrada de Domingo Belgrano, un hombre de negocios que llega a Buenos Aires a mediados de los años 1750 y se establece entre los principales notables de la ciudad. Para ello trabaja con 380 cartas enviadas, entre 1763 y 1796, por 134 personas desde 40 lugares de América y Europa. Estos 134 corresponsales hacen referencia a otras 486 personas, lo que supone 610 individuos más o menos ligados a dicho personaje.
} 
REDES- Revista hispana para el análisis de redes sociales

Vol. 21, \#4 Diciembre 2011

http://revista-redes.rediris.es

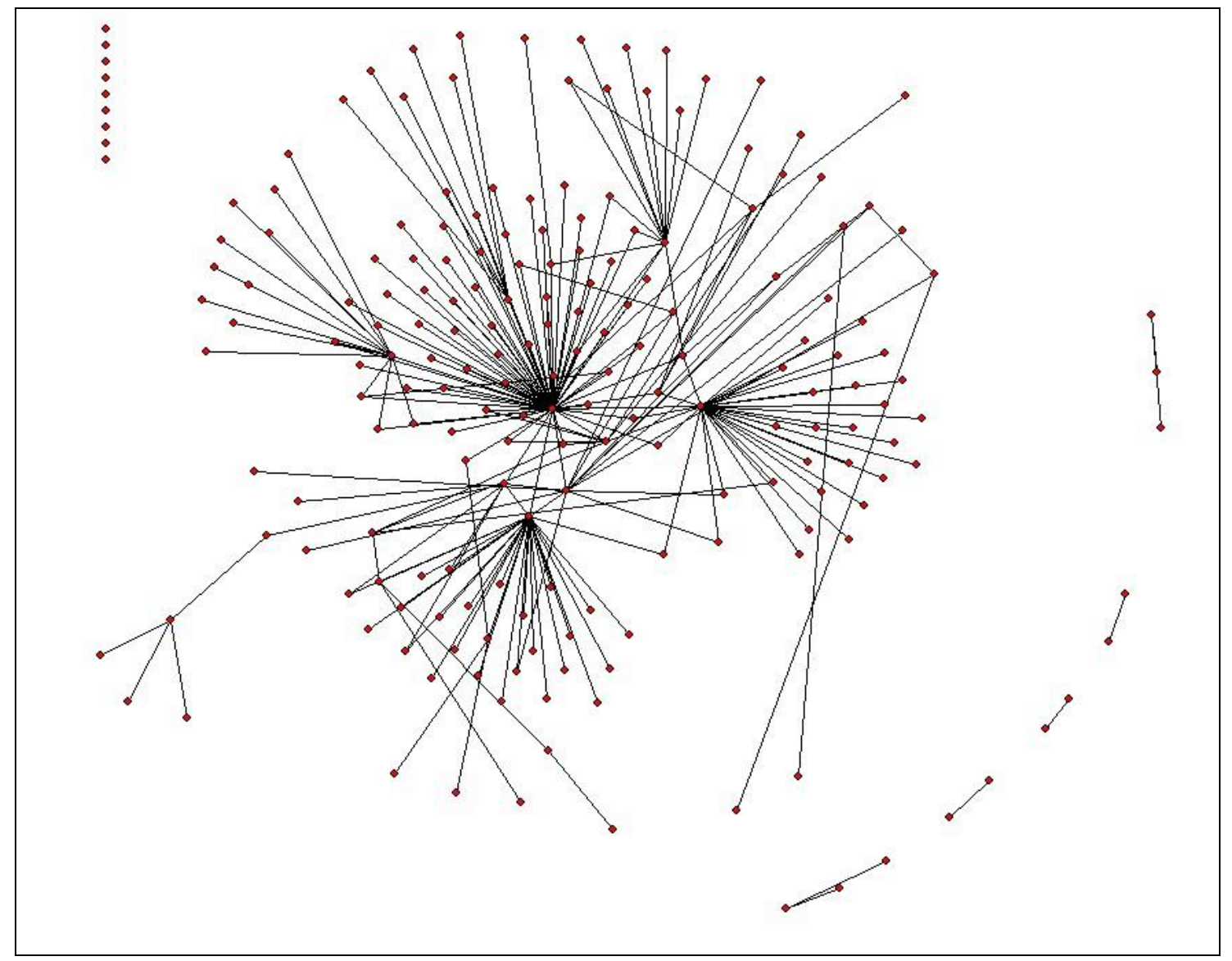

Diagrama 1. Estructura de la red social de Juan Vicente Marticorena en 1793

En este acercamiento, la inclusión de todos los individuos conectados con los corresponsales es importante para percibir las formas de articulación social que se pueden observar desde el punto de vista de ego. Para tratar de sus asuntos con este, cada corresponsal habla de otras personas, en su mayor parte conocidas por ambos. Algunas de ellas también le escriben cartas. Otras no, pero aparecen en las misivas de sus corresponsales. A veces de varios de ellos. Otros individuos, en cambio, sólo están vinculados a un corresponsal. Incluso algunos a ninguno, solo a ego: son los que figuran aislados -no conectados con ningún otro- en la parte superior izquierda del gráfico. De hecho, cada uno de estos corresponsales tiene su propia red de relaciones, de la cual sólo percibimos una pequeña parte a través de su correspondencia, aquella que está más o menos relacionada con ego (Moutoukias 2003a). 
REDES- Revista hispana para el análisis de redes sociales

Vol. 21, \#4 Diciembre 2011

http://revista-redes.rediris.es

El diagrama muestra lo que ve el receptor de las cartas, que no está incluido en él: el conjunto de interacciones directas o indirectas que percibe a través de su correspondencia. Se trata del conjunto de personas con las que está relacionado de forma directa o indirecta a través de este medio: sus contactos directos, pero también aquellos que sólo conoce a través de estos, en la medida en que, por medio de ellos, llegan noticias de terceras personas, se piden favores, circulan bienes y servicios, se articulan facciones políticas (Boissevain 1974) o circuitos mercantiles. Esta red no es algo cerrado ni completo, en la medida en que cada uno de esos individuos mantiene, a su vez, relaciones con otras personas que no interfieren en ella y que, por tanto, escapan a nuestra percepción. Sin embargo, nos da la visión que una persona tiene del conjunto de sus relaciones y de los contactos de estos, en la medida en que le afectan de un modo u otro (Moutoukias $\left.2003^{a}\right)$.

En este conjunto de interacciones aparecen tanto los individuos que están relacionados habitualmente entre sí como los que sólo entran en contacto de forma ocasional o excepcional, cualquiera que sea la "naturaleza" de sus vínculos (de parentesco, amistad, profesional, de negocios, de clientelismo, de afinidad ideológica...) y cualesquiera que sean los valores cambiantes de estas relaciones, entre la mayor cooperación y los más enconados conflictos. En este conjunto de interacciones, el análisis de redes detecta los "grupos" o "subgrupos" que pueden estar presentes en la red, aquellos en que los actores están más cercana y fuertemente conectados mutuamente, y observa cómo los componentes pequeños y cohesionados se articulan en redes de relaciones más amplias. También cómo los individuos están inmersos en la estructura de los grupos de una red: aquellos que tienen todas sus relaciones dentro de un único grupo, aquellos que actúan como puentes entre grupos, o aquellos puntos de corte claves sin los cuales la red se dividiría en partes desconectadas entre si $^{13}$. Muestra estas articulaciones no según los vínculos nominales (de familia, parentesco, amistad, etc.) que la historiografía tradicional supone que articulan el entramado social, sino desde las interacciones efectivas entre actores. Por supuesto, la valoración de todo ello requiere un atento análisis cualitativo de los contenidos de sus interacciones (Bidart, Charbonneau y Grossetti 2009).

\footnotetext{
13 Sobre indicadores de cohesión y subgrupos, y análisis de cohesión entre los tipos de subgrupos, McCarty 2010.
} 
REDES- Revista hispana para el análisis de redes sociales

Vol. 21, \#4 Diciembre 2011

http://revista-redes.rediris.es

Hemos dicho que una red no es una cosa, sino más bien un conjunto de individuos conectados de un modo u otro a través de interacciones efectivas que se producen en un momento dado. Por ello, no se trata de algo fijo, sino muy cambiante. Las interacciones que percibimos a través de las cartas corresponden a intercambios entre individuos en un determinado momento y varían, por tanto, de un momento a otro. Desde luego, la observación muestra que hay individuos que interactúan entre sí más constantemente, a lo largo de un periodo de tiempo más o menos amplio, colaborando en asuntos múltiples, mientras que otras relaciones son ocasionales o solo se activan en un momento para determinada operación.

Esta variabilidad vs. durabilidad de las redes sociales puede ser objeto de historia. El seguimiento de la correspondencia epistolar en el tiempo permite observar la evolución del conjunto de la red de relaciones a medida que los actores implicados construyen sus trayectorias y generan sus economías y vinculaciones. Para analizar la evolución de la red de Juan Vicente de Marticorena, Lara Arroyo ha efectuado varios cortes cronológicos, tras buscar momentos de corte estratégicos mediante una observación cualitativa de la correspondencia: De julio de 1783 a diciembre de 1784: 171 cartas. En 1789: 178 cartas. En 1793: 115 cartas. En 1805: 104 cartas. Aunque no se utilice aquí, esta secuencia permite captar la dinamicidad y el cambio en una red social a medida que la acción de los actores los producen, esto es, muestra la dinámica de construcción por los individuos tanto de sus vínculos como de las configuraciones sociales más amplias que generan con su acción ${ }^{14}$. Esto tiene interesantes aplicaciones para la explicación de dinámicas de cambio que no podemos abordar aquí.

Por lo tanto, en el ejemplo que nos ocupa, el diagrama de la red de Juan Vicente de Marticorena en 1793 muestra la parte de la red de ego que está interactuando en un momento dado en torno a determinados tratos. En este caso, una buena parte de las interacciones corresponde a las relaciones que se activan en esos meses en torno a dos asuntos concretos que, por su importancia para la familia, movilizan bastantes energías. El primer asunto consiste en conseguir una ejecutoria de hidalguía para el hermano Juan Bautista, al que se le presenta la oportunidad de efectuar un excelente matrimonio en Guatemala, con una hija del marqués de Aycinena, pero con la condición de que obtenga dicha ejecutoria para que pueda heredar el mayorazgo. El segundo tema destacado consiste en intentar conseguir una comandancia en Lima para otro hermano, Juan Miguel Marticorena. Ambos

\footnotetext{
${ }^{14}$ Una observación de qué pasa en una red con el transcurso del tiempo, cuando se establecen nuevas relaciones, se rompen otras o se incluyen nuevos actores, a través de cortes cada diez años en una red de poder, en Ruiz León y Gil-Mendieta 2007.
} 
REDES- Revista hispana para el análisis de redes sociales

Vol. 21, \#4 Diciembre 2011

http://revista-redes.rediris.es

asuntos les llevan a interactuar con individuos establecidos en diversas instituciones y geografías ${ }^{15}$. Estos casos son especialmente interesantes porque revelan las conexiones personales de estos grupos de "comerciantes" en la Corte y en diversas instituciones de gobierno de la Monarquía. Ejemplos como estos sugieren el interés de hacer "cortes" en torno a asuntos que revelan las conexiones entre diferentes esferas, en este caso las relaciones privilegiadas entre los "negocios" y el patronazgo político, con el fin de conseguir el ascenso social.

\section{Las técnicas de trabajo. El vaciado de la correspondencia y el tratamiento informático}

Las técnicas de trabajo y los instrumentos informáticos son, sin duda, conocidos por los especialistas, pero no por los profanos ni por la gran mayoría de historiadores. Por ello, nos parece útil exponer brevemente y de la manera más sencilla posible cómo se ha procedido y qué instrumentos se han utilizado.

Para reconstruir una red egocentrada conviene trabajar con un epistolario lo más completo posible. Para ello, se vacían todas las cartas que recibe ego en un breve lapso de tiempo, puesto que se trata de observar las interacciones entre individuos que interactúan en un mismo presente histórico. El vaciado de las cartas se hace por individuos. Se vacían todas las interacciones de cada uno de ellos. Esto es: de cada uno de los corresponsales que escribe, de cada una de las personas a las que estos se refieren, y de cada uno de los individuos con los que aquellas, a su vez, interactúan. En la correspondencia, son frecuentes las expresiones en que los corresponsales muestran una concatenación de relaciones que es necesario descomponer en el vaciado. Así, por ejemplo, en la carta en que Juan Bautista Marticorena relata cómo ha sido solicitado por el marqués de Aycinena para casar con su hija:

"Que en sustancia fui solicitado por el señor Marqués por medio de nuestro amigo Micheo a quien se le insinuó sumamente pagado de mis prendas y circunstancias manifestándole se alegraría infinito pues yo vecino de esta y como quejándose de su suerte de que no hubiese puesto los ojos en su hija mayor que va para seis meses casó con D. Tadeo Piñol lo que comunicándome por dicho amigo Micheo y hechas mis composiciones de lugar al cabo de algún tiempo resolví al pedirla por medio del mismo amigo y en efecto tuve la gran satisfacción de que el señor marqués me diese el Sí (...)"

\footnotetext{
${ }^{15}$ Un intento de cruzar los datos de las redes personales con la distribución espacial de los actores, y los intercambios asociados, en Molina, Ruiz y Teves 2005.
} 
REDES- Revista hispana para el análisis de redes sociales

Vol. 21, \#4 Diciembre 2011

http://revista-redes.rediris.es

Parecida secuencia de relaciones, que es necesario descomponer, se observa en esta carta que envía Gabriel de Arozarena, desde Vitoria, en relación con la petición de la comandancia de Lima para uno de los hermanos Marticorena:

"Me alegro que haya vuestra merced hecho su instancia por el conducto que le ha indicado nuestro paisano Olleta" (...) "aunque me avisó del nombre y apellido de la parienta de Olleta escribí con suma reserva a mi sobrino para que indagase su poder y conexiones".

Existen varios programas informáticos que permiten recoger todos los datos en una matriz, realizar los gráficos pertinentes y calcular los parámetros de una red social. El más sencillo es Ucinet. Se trata de una matriz $x / y$, en cuyas filas y columnas se introducen los nombres de todos los actores de la muestra. En las casillas en las que se cruzan los diferentes individuos se introducen los datos correspondientes. Si hay una relación entre ellos (1) o no (0). O el número de interacciones entre ellos en dicho período de tiempo.

Una vez completada la matriz, el programa representa el "grafo" o forma de la red, situando en un mismo plano el conjunto de personas que, de un modo u otro, interactúan en relación con ego. Cada individuo está representado por un nodo y cada relación por una línea entre nodos. El programa sitúa con mayor centralidad los nodos mejor conectados con otros y discrimina aquellos que se sitúan en la periferia de la red (Brandes, Kenis y Raab 2005). Dicho diagrama será eficaz en la medida en que exprese de manera legible y lo más clara posible la forma de la red y la articulación de sus diferentes elementos o partes. Al fin y al cabo, se trata sólo de una representación.

Para completar la información, el programa permite introducir atributos de los actores, tales como el sexo, la edad, la profesión, etc. Para generar atributos múltiples, basta crear una tabla con los nombres de los actores y destinar una columna para cada atributo, dando valores numéricos a los individuos según su calidad. Por ejemplo, 1 para los varones y 2 para las mujeres. Con esta información, el programa permite representar la red diferenciando a los actores o grupos de actores con distintos colores o formas. Dado que el gráfico no es sino un instrumento para sintetizar y expresar una realidad compleja, parece preferible evitar los excesos que puedan perjudicar su eficacia expresiva. 
REDES- Revista hispana para el análisis de redes sociales

Vol. 21, \#4 Diciembre 2011

http://revista-redes.rediris.es

El programa informático permite calcular una serie de variables que miden las características de la red en su conjunto y las posiciones que ocupan en ella cada uno de los actores o grupos de actores. Estos parámetros sirven para caracterizar y comparar las estructuras de diferentes redes y van desde los más elementales, como la talla de la red, o número de personas implicadas, la frecuencia de las relaciones, o número de interacciones en un periodo, y la dirección, o sentido de las relaciones, hasta otros más complejos (Molina 2001, pp.32ss.).

Tres parámetros son especialmente importantes en el análisis de redes sociales, la densidad, la centralidad y la mediación (Wasserman y Faust 1994, Carrington, Scott y Wasserman 2005), y su aplicación a la historia nos parece particularmente útil. La densidad se mide por el porcentaje de relaciones efectivas de cada individuo con respecto al número máximo de relaciones posibles en la red. Muestra la alta o baja conectividad de la red en su conjunto y permite observar cuáles son sus partes más densas (los individuos que están más conectados entre sí) y cuáles las partes más alejadas de ellas.

La centralidad y la dispersión muestran la posición de cada actor o grupo de actores en los intercambios de la red: las conexiones privilegiadas y las posiciones periféricas en dichos intercambios. El grado de centralidad se mide por el número de individuos de la red con los que un actor está directamente relacionado. Sirve para observar quiénes tienen una posición central en los intercambios de la red y quiénes ocupan, al contrario, una posición periférica y necesitan pasar por los nodos centrales para conectarse con otros. La centralidad revela, por tanto, los núcleos de mayor influencia en la red con respecto a los elementos más periféricos (Cook 1990, Fombrun 1983).

La mediación y la accesibilidad consideran la circulación en la red y los mediadores que sirven de nexo entre grupos y subgrupos. El grado de intermediación (Betweenness) viene dado por el número de pares de nodos que un actor es capaz de conectar. Revela quiénes son los mediadores o actores-puente y su capacidad de intermediación y de control de la comunicación. El grado de cercanía (Closenness) es la capacidad de un actor para alcanzar a todos los nodos de la red y se calcula contando las distancias que necesita un actor para llegar a los demás. 
REDES- Revista hispana para el análisis de redes sociales Vol. 21, \#4 Diciembre 2011

http://revista-redes.rediris.es

Sin entrar en mediciones específicas, vamos a intentar visualizar estos aspectos a través del diagrama de la red de Juan Vicente de Marticorena. En particular, nos vamos a centrar en las diferencias de "densidad" que refleja dicho diagrama, con la idea de combinar esta percepción general con la información cualitativa de las cartas, de modo que podamos mostrar a qué corresponden, en la práctica, esas diferencias de densidad: qué economía se mueve a través de estas relaciones y qué parte de esta economía se mueve a través de qué relaciones.

\section{El entorno denso y las partes más alejadas de la red}

La red de Juan Vicente de Marticorena muestra unas partes más densas que otras. Hay individuos que están más estrechamente conectados entre sí, mientras que otros ocupan posiciones periféricas, alejadas de este entorno más denso.

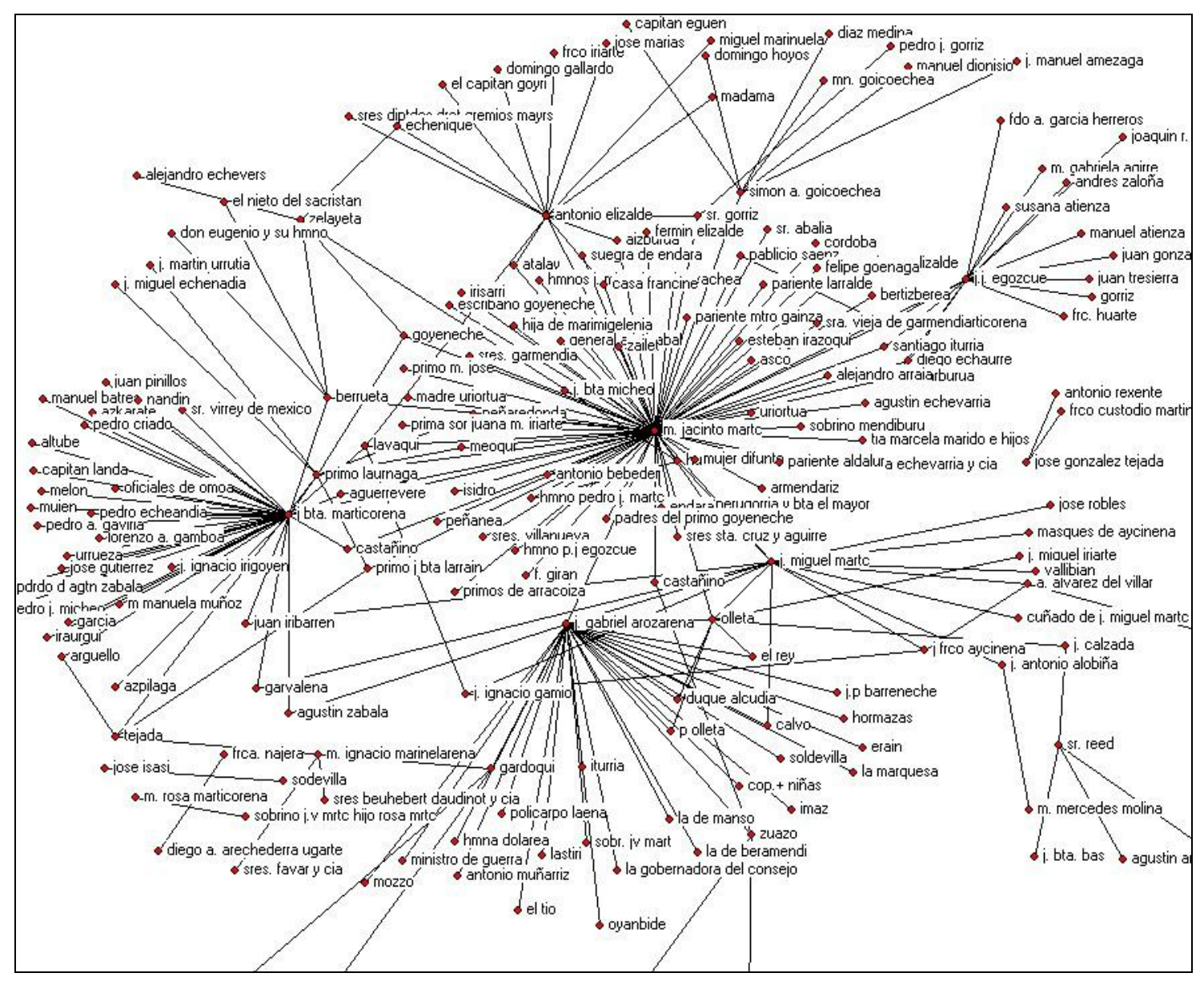

Diagrama 2. Partes más densas de la red de Juan Vicente Marticorena 
REDES- Revista hispana para el análisis de redes sociales

Vol. 21, \#4 Diciembre 2011

http://revista-redes.rediris.es

En el diagrama n०2 se pueden percibir las partes más densas de la red. Vemos a una serie de individuos que están más conectados entre sí. Estos individuos ocupan una posición central en la circulación de recursos, noticias y favores. La lectura cualitativa de sus interacciones muestra la variedad de funciones que asumen y los contenidos múltiples de sus intercambios. En estas posiciones destacan los actores que, en este momento, movilizan los principales asuntos. Recordemos que estos eran dos: conseguir en el Consejo Real de Navarra una ejecutoria de nobleza para que Juan Bautista Marticorena pudiera casar con una hija del marqués de Aycinena, en Guatemala, y obtener una comandancia en la Audiencia de Lima para el hermano Juan Miguel. En ambos asuntos observamos a una serie de actores, muy conectados entre sí, como Juan Gabriel Arozarena, Leonardo Olleta, Berrueta, Egozcue o los propios hermanos Juan Vicente, Juan Miguel y Miguel Jacinto de Marticorena, que ocupan posiciones centrales, mueven varios negocios simultáneamente, y, para ello, movilizan, a su vez, a muchos otros individuos para conseguir sus fines. El diagrama no 3 visualiza a estos actores centrales que están especialmente conectados entre si y movilizan a otros sujetos. 


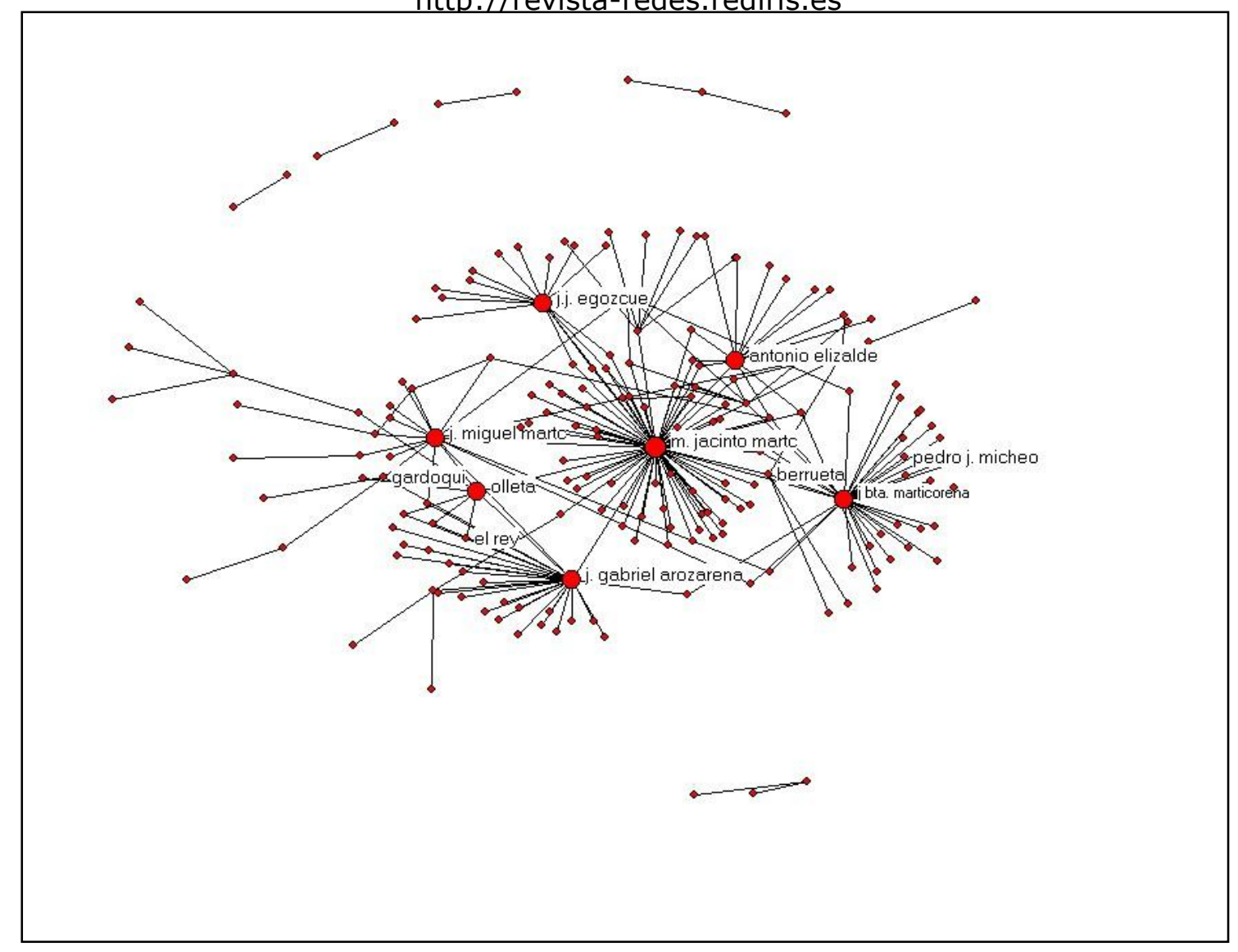

Diagrama 3. Actores centrales en la red.

Veamos a qué corresponde esta configuración relacional en la documentación epistolar. En cuanto a la ejecutoria de nobleza, la movilización comienza con la misiva que Juan Bautista Marticorena envía a su hermano Juan Vicente, desde Guatemala, en 1792, en la que le pide que le consiga dicha ejecutoria de hidalguía:

"Mi querido Juan Vicente... Vamos al caso. Los hombre en llegando a cierta edad es preciso que piensen y determinen el estado que han de tomar. En esta virtud yo he escogido el del matrimonio con Doña María Josefa Aycinena hija del Marqués de ese título y de Micaela de Najera, ya difunta a quien sin duda la conocerías en el tiempo que estuviste en esta; Y para que llegue a efectuarse el enlace sólo resta (según me ha dicho el mismo señor marqués) el que la Niña cumpla los 17 años teniendo ya 16 y como cuatro meses y el que me envíes los papeles de la hidalguía y nobleza por cuanto hay que presentarlo a la Real Audiencia para que reconocidos y vistos quede la niña con opción al Mayorazgo cuyo derecho perderá a no practicarse esta diligencia....

...Por si para la consecución de los papeles tuvieses que hacer algunos gastos considerables, haré todo el empeño para mandarte una libranza de mil pesos por inmediato correo, pero mira que no dejes de remitírmelos con la mayor prontitud, cuya fineza espero merecértela pues aunque tengo de mi poder los de limpieza de Sangre que en días pasados me los despachó D. Juan de Iribarren rector de Echalar, según me dice Micheo no son bastante para presentar a la Audiencia." 
REDES- Revista hispana para el análisis de redes sociales

Vol. 21, \#4 Diciembre 2011

http://revista-redes.rediris.es

Esta carta va a poner en marcha una serie de relaciones en España para la obtención de dicha ejecutoria en el Consejo Real de Navarra. Para ello, el hermano Juan Vicente tendrá que movilizar a una serie de contactos con el fin de conseguirla a la mayor brevedad posible. Egozcue y Miguel Jacinto Marticorena fueron los encargados de realizar todas las diligencias oportunas. Miguel Jacinto Marticorena viajó de Veracruz a Navarra para ocuparse personalmente del asunto. Durante estos primeros meses de 1793, ambos hacen una serie de encargos a los amigos Huarte, Gorriz, Berrueta y Celayeta para la consecución de la ejecutoria. Tras múltiples gestiones, Miguel Jacinto escribe desde Pamplona el 26 de julio, narrándole a su hermano Juan Vicente los resultados positivos de toda esta actividad: "los papeles de nuestra hidalguía ya están impresos y el martes me dice Huarte estarán firmados y sellados por los individuos de este tribunal y los 4 llevaré conmigo será menester pasar por el Consejo de Castilla cuando vaya a Madrid..."16. Finalmente, Juan Bautista Marticorena pudo casar en Guatemala con la hija del Marqués de Aycinena, en 1794.

El segundo asunto principal de estos meses consistía en intentar obtener una comandancia de la Audiencia de Lima y moviliza a individuos de la red especialmente conectados con la Corte, como Juan Gabriel de Arozarena y Leonardo Olleta, que se conciertan entre si y movilizan, a su vez, a otros actores, como se refleja en el diagrama no 4 .

${ }^{16}$ Archivo General de Indias, Sección Consulados 433-438 
REDES- Revista hispana para el análisis de redes sociales

Vol. 21, \#4 Diciembre 2011

http://revista-redes.rediris.es

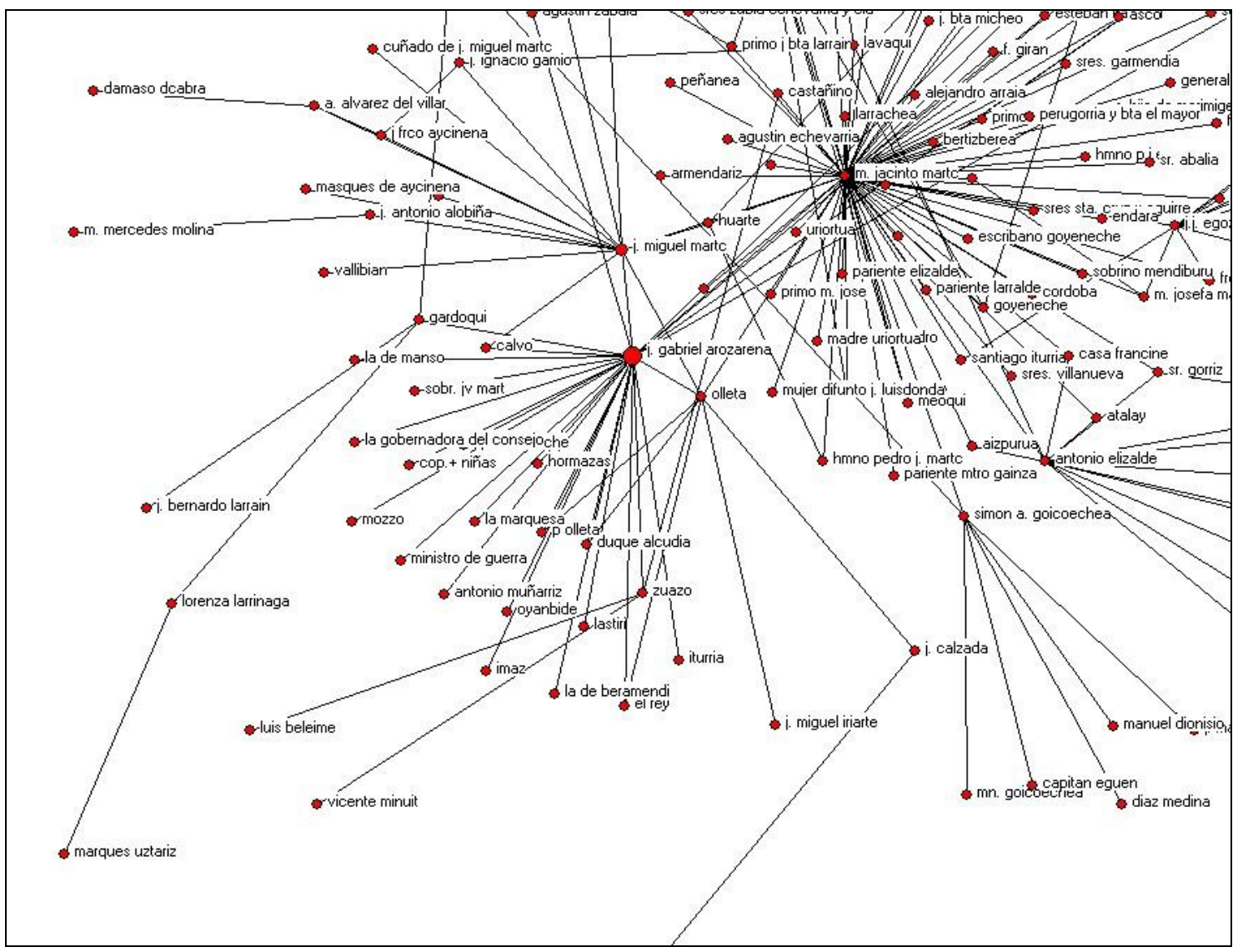

Diagrama 4. La red de Juan Gabriel Arozarena en relación a los principales asuntos que trata

Juan Gabriel Arozarena ${ }^{17}$ era miembro de un grupo de parientes, amigos y paisanos baztaneses muy establecido en la Corte y en la Administración de la Real Hacienda. Desde Vitoria, donde se hallaba en 1793 como administrador general de rentas, escribe a Juan Vicente en Cádiz un total de 32 cartas, en torno a diversos asuntos. En particular, está en contacto con los círculos de la Corte: con Juan Pedro de Barrenechea, su sobrino y principal informante en Madrid, con el marqués de las Hormazas, Iturria, Erain, el general Gardoqui, Lastiri, incluso el propio rey.

Leonardo de Olleta, por su parte, es un paisano y amigo de Juan Vicente de Marticorena que intenta obtener el favor del duque de Alcudia, Manuel de Godoy -el favorito de Carlos IV-, a través de una parienta suya que trabajaba en casa del duque. Así escribía a Juan Vicente, dando cuenta de sus gestiones: "Por más que en varías cartas he tocado a mi parienta sobre la comandancia de Lima que se quería solicitar para el sr. Juan Miguel (...) sobre aquella me dice mi parienta lo que verá usted por la adjunta y sobre el segundo particular no ha podido todavía contestarme esto sobre si la gratificación de sesenta mil reales será bastante para

\footnotetext{
17 Natural de Arízcun, en 1785 era vista 70 de la aduana de Cádiz y, desde 1792, administrador general de las Rentas Generales de Vitoria, desde donde escribe en este momento a su paisano Juan Vicente Marticorena. A partir de 1799 será Consejero del Consejo de Hacienda hasta su muerte en 1807. Base de datos Fichoz.
} 
REDES- Revista hispana para el análisis de redes sociales

Vol. 21, \#4 Diciembre 2011

http://revista-redes.rediris.es

el logro de la comandancia de Lima...". En julio de 1793, Olleta vuelve a dirigirse en estos términos a Juan Vicente Marticorena "la carta de recomendación que me remite para la mujer del gobernador de esta plaza es de la madre del Duque de la Alcudia y la recomendación que se me ofrece para el señor Marqués de Ustariz nuevo intendente de Sevilla será según parece del sr Moreno casado con la hermana de dicho señor Duque..." En este caso, los interesados no consiguen la comandancia Lima para los Marticorena.

En contraste con lo anterior, el diagrama no 5 muestra partes más periféricas de la red de Juan Vicente Marticorena en que una serie de individuos no están conectados con los demás, sino con una sola persona que hace de mediador y los conecta de algún modo a la parte más densa de la red. En el diagrama, estas partes tienen una forma característica de estrella, que está muy presente en redes mercantiles como la de los Marticorena o la de Belgrano. En este caso se trata de proveedores o de compradores de un territorio conectados con el agente o factor de la casa de comercio que opera en él y que canaliza su flujo de productos y servicios en dicho territorio. Por ejemplo, el Sr. Reed, desde Alicante, es el mediador de otros individuos como Juan Bautista de Bas, Agustín Arauce o los factores de Reus, con los que vehicula asuntos mercantiles principalmente. Así mismo, Simón Antonio de Goicoechea es otro de los mediadores de temas comerciales, algo alejado de las conexiones centrales pero que conecta a diferentes actores del comercio con Juan Vicente Marticorena. 
REDES- Revista hispana para el análisis de redes sociales

Vol. 21, \#4 Diciembre 2011

http://revista-redes.rediris.es

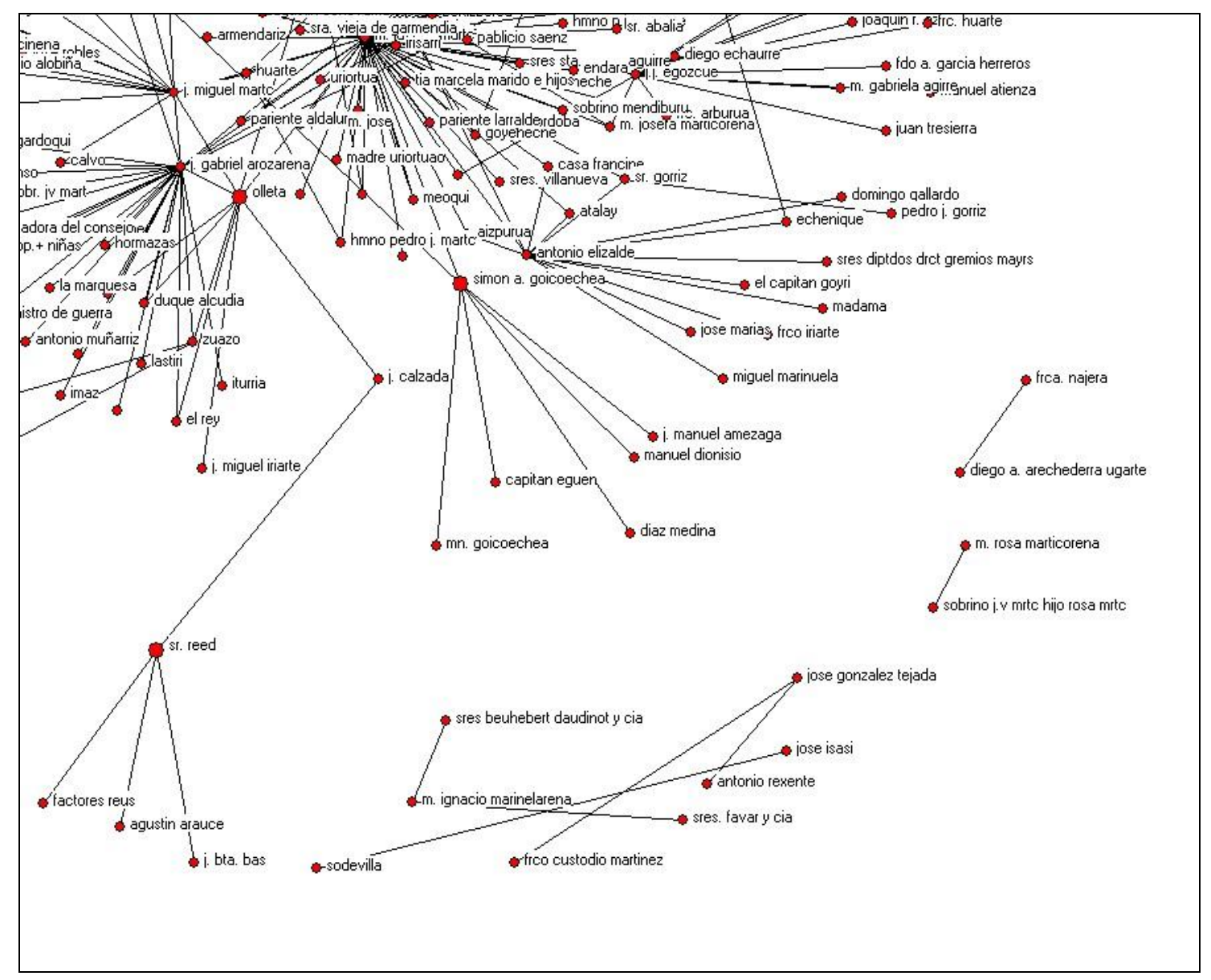

Diagrama 5. Partes más periféricas de la red.

\section{Reflexiones finales}

La correspondencia epistolar nos parece una fuente privilegiada tanto para el análisis cualitativo de las relaciones personales como para la reconstrucción de redes egocentradas. Evidentemente, con las inevitables limitaciones que hemos señalado, unas específicas de la correspondencia y otras comunes a toda fuente documental.

En el texto hemos tratado de mostrar, al hilo de dos ejemplos, ambas aplicaciones. Debatir sobre cual de ellas es mejor no tiene sentido. Cada metodología es un instrumento y sólo tiene interés en la medida en que se adecue y sirva al fin deseado. Ambos acercamientos ven cosas diferentes y la combinación de ambos nos parece la mejor opción. Dicho esto, con respecto al análisis cualitativo de los lazos personales, más clásico y conocido en la práctica historiográfica, el análisis de redes egocentradas permite ver, o ver mejor, cosas que de otro modo no veríamos, o solamente de forma muy parcial e impresionista. Procura una buena base para situar mejor, en su contexto relacional complejo, el trabajo cualitativo. Pero, sobre todo, aporta dos cosas específicas que merece la pena subrayar para concluir: una 
REDES- Revista hispana para el análisis de redes sociales

Vol. 21, \#4 Diciembre 2011

http://revista-redes.rediris.es

percepción aguda de las configuraciones relacionales y de su conectividad, y una percepción de globalidad, con respecto a las concepciones planas o sectoriales de una red social.

El "análisis de redes" (en este caso en su versión de "redes egocentradas") es especialmente apto para percibir todo lo relativo a la conectividad y los aspectos relacionados con ella: las características de las configuraciones relacionales, pero también su influencia en los comportamientos de los individuos y su incidencia en los procesos económicos, sociales y políticos. Las diferencias en cómo los individuos están conectados inciden en sus oportunidades y limitaciones, y las características de su inserción social tienen mucho que ver con sus comportamientos. Las aplicaciones de estos elementos son especialmente útiles, en sociología como en historia, para analizar fenómenos como la circulación y distribución de recursos y oportunidades, la articulación de la cooperación y del conflicto, las dimensiones relacionales del poder y las articulaciones socio-políticas, la relación entre la densidad del entorno y los comportamientos con respecto a las normas y valores de un grupo, o la disposición de una sociedad o de un segmento social a la reproducción o al cambio. Si la función final del historiador es explicar procesos de cambio, entendemos que estos conceptos e instrumentos son útiles para observar en qué encuentros y experiencias compartidas se generan los cambios, a través de qué relaciones se difunden, qué sectores quedan al margen y cuáles resisten o se enfrentan abiertamente a ellos.

El ejemplo de la red de Juan Vicente de Marticorena confirma las observaciones de Zacarías Moutoukias sobre la pertinencia del análisis de redes egocentradas con respecto a los trabajos clásicos sobre "historia de la familia" y con respecto al concepto plano de "redes familiares" (Moutoukias 2000, 1995). Al mismo tiempo, la observación cualitativa de la red de Pedro José Gastón de Iriarte (pero también de la de Juan Vicente Marticorena) permite integrar y complementar mejor la percepción de las relaciones personales desde la "historia de la familia" con el efectivo "análisis de redes sociales". Esta síntesis nos parece importante para integrar los "análisis de redes" -marginales todavía en la historiografía- en una historia social más general (como hemos intentado en Imízcoz 2011a).

La aproximación a las "redes sociales" a partir de la "historia de la familia" observa con relativa facilidad el núcleo más denso de relaciones de parentesco, amistad, vecindad, etc. en torno a la familia, pero, por lo general, le resulta difícil percibir las relaciones alejadas de ese entorno. Construir análisis de redes a partir de la familia y de su entorno relacional tiene sentido, en la medida en que históricamente esta 
REDES- Revista hispana para el análisis de redes sociales

Vol. 21, \#4 Diciembre 2011

http://revista-redes.rediris.es

ha sido una institución medular por la centralidad y pluralidad de sus funciones. En efecto, alrededor de la familia observamos un entorno denso, compuesto por los parientes y amigos que eran parientes y amigos entre sí. Las relaciones de este entorno inmediato cumplían funciones múltiples (afectivas, de compañía, de cooperación económica, laborales, de ocio, educativas, informativas, de regulación y disciplina social, de solidaridad y defensa en los conflictos, etc), y por ello tenían una centralidad especial para la vida de los individuos. En este entorno se superponían diversas esferas normativas, como la familia, la corporación laboral, la comunidad local o la iglesia. Los parientes cercanos y los amigos íntimos eran muchas veces, al mismo tiempo, vecinos, colegas de trabajo, compañeros de ocio, miembros de una misma cofradía o asociación, feligreses de una misma parroquia. Este entorno denso correspondía normalmente a espacios sociales relativamente próximos, con diferencias de estatus social limitadas (Moutoukias 2003b, pp.189195). Aquí, la "condición social" y las "relaciones" tendían a coincidir, en la medida en que, en cada estatus, las pautas más habituales de endogamia matrimonial y profesional solían comportar alianzas y amistades que reforzaban la homogeneidad y coherencia del grupo. La densidad de este entorno favorecía la conformidad de sus miembros con las reglas y valores del grupo, así como las posibilidades de presión para que los individuos adecuasen sus comportamientos a dichas reglas (Bott 1990). En este entorno, la cooperación solía ser particularmente intensa, pero también los conflictos resultaban especialmente graves, por todo lo que estaba en juego (Granovetter 1985). Todo ello se puede observar a través de las fuentes locales, pero también en la distancia, a través de la correspondencia epistolar, como muestra, en ambos ejemplos, la fuerza de las relaciones de parentesco por encima de la separación geográfica.

Sin embargo, esta percepción deja fuera cosas importantes. Una red egocentrada como la de Juan Vicente Marticorena nos acerca al conjunto de relaciones con las que ego interactúa directa o mediatamente a través de la correspondencia epistolar $y$, especialmente, a las relaciones más alejadas de su entorno inmediato. Esto es fundamental para captar cosas como la circulación general de recursos y sus consecuencias. También sus efectos en el entorno inmediato, en la esfera local. Como hemos podido observar cualitativamente, a través de la correspondencia epistolar de Pedro José Gastón de Iriarte, esto revela con gran nitidez cosas que de otro modo no se veían, como la manera en que determinadas relaciones en la corte contribuyen a alimentar hegemonías locales, o a producir élites en América, o cómo actividades en el comercio atlántico e indiano alimentan economías en comunidades locales del norte de España, o como los humildes parentescos y amistades de 
REDES- Revista hispana para el análisis de redes sociales

Vol. 21, \#4 Diciembre 2011

http://revista-redes.rediris.es

aldeas aparentemente tan periféricas están en el origen de redes de poder de especial centralidad en la corte y en el imperio.

Globalidad, en fin. El análisis de redes egocentradas considera el conjunto de las interacciones, mientras que otro tipo de trabajos se centra en considerar las relaciones que se producen en un mismo plano o institución. Privado del conjunto relacional en que se inscribe su observación, el análisis cualitativo de las relaciones personales tiende a insertarse en los marcos institucionales o en las categorías explicativas que vienen dadas por la tradición historiográfica, como "familia" y "parentela", "paisanaje", "comercio", "administración", "gobierno", "iglesia", "asociación" o "esfera cultural". Luego, al hablar de redes desde esta óptica, es habitual referirse, según los casos, a "redes familiares", "redes de paisanaje", "redes mercantiles", "redes políticas", "redes societarias" o "redes intelectuales". Este procedimiento nos informa sobre las relaciones en un mismo plano $y$, como tal, no deja de ser útil y válido para analizar dicho plano. Sin embargo, la realidad es poliédrica, se compone de muy diversos planos que se intersectan, no sabemos muy bien de qué manera. La virtualidad de la correspondencia epistolar y de la perspectiva egocentrada es que nos muestran cómo. Con respecto a la separación habitual en planos, la reconstrucción de redes egocentradas a partir de la correspondencia nos acerca a una percepción global del universo relacional de los actores sociales, con el conjunto complejo de sus interacciones, la pluralidad de elementos que transitan a través de ellas y las conexiones entre esferas que produce y revela su acción.

El análisis de redes egocentradas considera el conjunto de las interacciones, cualesquiera que sean los planos en que se producen. Esto es especialmente importante en las sociedades del Antiguo Régimen, caracterizadas por el predominio de configuraciones en las que un mismo vínculo cumple una pluralidad de funciones. A través de los individuos que juegan roles múltiples se encabalgan varios campos institucionales como la familia, el comercio, la administración, los partidos políticos, etc. El análisis de redes ego-centradas permite aprehender este encabalgamiento para explicar las configuraciones complejas y la dinámica social, superando las "segmentaciones" sociales o institucionales clásicas (Moutoukias 2003b pp.189-195). 
REDES- Revista hispana para el análisis de redes sociales

Vol. 21, \#4 Diciembre 2011

http://revista-redes.rediris.es

Este tipo de análisis procura una percepción de globalidad, en la medida en que permite observar el conjunto de relaciones de un individuo en las diferentes esferas de actuación en las que participa y cómo estas se afectan unas a otras. La idea que se halla en la base es la de la unidad del sujeto, con sus vínculos e interacciones en una pluralidad de esferas, que se afectan mutuamente. En este sentido, los individuos pueden ser tomados como actores de una historia global, en la medida en que, a través de sus acciones y relaciones, percibimos no solamente la articulación social, sino la coherencia interna de esa historia que es la suya, esto es, la relación efectiva, en cada caso y en cada momento, entre sectores de actividad, espacios o esferas (económica, política, cultural, etc.) cuyos funcionamientos percibimos habitualmente de forma segmentada (Imízcoz 2004).

\section{Bibliografía}

Annales de Démographie Historique (2005), "Histoire de la famille et analyse de réseaux", n01.

Antón Pelayo, J. (2005), La sociabilitat epistolar de la familia Burgués de Girona (1799-1803), Girona, Cercle d'Estudis Històrics i Socials de Girona.

Arroyo Ruiz, L. (2007), "Redes de influencia. Relaciones privilegiadas en el comercio colonial a finales del siglo XVIII: los Marticorena y su correspondencia epistolar", Nuevo mundo, nuevos mundos, n07.

Arroyo Ruiz, L. (2010), "La casa Marticorena: Economía doméstica y redes sociales en el comercio colonial de la segunda mitad del siglo XVIII", en J.M. Imízcoz Beunza y O. Oliveri Korta (coord.), Economía doméstica y redes sociales en el Antiguo Régimen, Madrid, Silex, pp. 357-392.

Beaurepaire, P.-Y. (ed.) (2002), La Plume et la Toile. Pouvoirs et réseaux de correspondance dans l'Europe de Lumières, Arras, Artois Presses Université.

Beaurepaire, P.-Y. ; Taurisson, D. (eds.) (2003), Les Ego-documents à I'heure de l'électronique. Nouvelles approches des espaces relationnels, Université Paul Valéry- Montpellier III.

Beaurepaire, P.-Y. ; Häseler, J. (ed.) (2006), Les réseaux de correspondance à l'âge classique, XVIe-XVIIIe siécle, Publ. de Saint-Etienne.

Bergamasco, L. ; Bossis, M. (dir.) (2007), Archive épistolaire et Histoire, Cérisy, Editions Connaissances et Savoirs.

Bertrand, M., "De la familia a la red de sociabilidad", en Revista Mexicana de Sociología, vol 61, núm. 2, México, 1999

Bidart, C.; Charbonneau, J; Grossetti, M. (2009), "Las relaciones: la sustancia de las redes sociales", Redes-Revista hispana para el análisis de redes sociales, vol. 16 (http://revista-redes.rediris.es)

Boissevain, J. (1974), Friends of Friends, Oxford, Basil Blackwell.

Bott, E. (1990), Familia y red social. Roles, normas y relaciones externas en las familias urbanas corrientes, Madrid, Taurus.

Brandes, U.; Kenis, P.; Raab, J. (2005), "La explicación a través de la visualización de redes", Redes-Revista hispana para el análisis de redes sociales, vol. 9, (http://revista-redes.rediris.es) 
REDES- Revista hispana para el análisis de redes sociales

Vol. 21, \#4 Diciembre 2011

http://revista-redes.rediris.es

Carrington, P.J.; Scott, J.; Wasserman, S. (2005), Models and Methods in Social Network Analysis, New York, Cambridge University Press.

Caula, E. (2000), Tramas familiares y configuraciones mercantiles de origen vasco en el pasaje del orden político colonial al revolucionario. El Río de la Plata entre 1776 y 1820, tesis doctoral, Universidad del País Vasco (inédita)

Cook, K.S. (1990), "Linking actors and structures: An Exchange network perspective", en C. Calhoun, M.R. Scott (eds.), Structures of Power and Constraint. Papers in Honor of Peter M. Blau, New York, Cambridge University Press, 1990, pp. 113-128

De Federico, A. (2004), "Los espacios sociales de la transnacionalidad. Una tipología de la integración relacional de los migrantes", ", Redes-Revista hispana para el análisis de redes sociales, vol. 7 (http://revista-redes.rediris.es)

De Grande, P.; Eguía, M. (2008), "Reconstruyendo la red de lazos personales. Metodología egocéntrica para investigación sociométrica", ", Redes-Revista hispana para el análisis de redes sociales, vol. 15 (http://revista-redes.rediris.es)

Degenne, A.; Forsé, M. (1994), Les réseaux sociaux. Une analyse structurale en sociologie, Paris, A. Colin.

Díaz, B.; Siess, J. (2006), L'épistolaire au féminin. Correspondances de femmes (XVIII-XXe siècles), Presses Universitaires de Caen.

Epstein, A.L. (1969), "Gossip, Normas and Social Network", en J.C. Mitchell (ed.), Social Networks in Urban Situations, Manchester, Manchester University Press, pp.117-127.

Erickson, B.H (1997), "Social Networks and History. A Review Essay", Historical Methods, vol. 30, n03, pp. 149-157.

Ferrand, A. (2002), "Las comunidades locales como estructuras meso", RedesRevista hispana para el análisis de redes sociales, vol. 3 (http://revistaredes.rediris.es)

Fombrun, C.J. (1983), "Attributions of power Across a Social Network, Human Relations, vol.36-6, pp. 493-508

García Mouton, P. (1996-1997), "Las mujeres que escribieron cartas desde América (ss. XVI-XVIII)" en Anuario de Lingüística Hispánica, XII, pp. 319-326.

García-Valdecasas Medina, J.I. (2011), "Una definición estructural de capital social", Redes-Revista hispana para el análisis de redes sociales, vol. 20 (http://revistaredes.rediris.es)

González Gómez, C.I ; Basaldúa Hernández, M. (2007), «La formación de redes sociales en el estudio de actores y familias. Perspectiva de estudio en historia y antropología", Redes-Revista hispana para el análisis de redes sociales, vol. 12 (http://revista-redes.rediris.es)

Gourdon, V.; Beauvalet, S.; Ruggiu, F.-J. (dir.) (2004), Liens sociaux et actes notariés dans le monde urbain en France et en Europe, Paris, Presses de I'Université de Paris-Sorbonne.

Granovetter, M.S. (1973), "The Strength of Weak Ties", American Journal of Sociology, 78, pp.1360-1380

Granovetter, M.S. (1982), "The Strength of Weak Ties: a Network Theory Revisited", en Peter V. Marsden, Nan Lin (eds.), Social Structure and Network Analisys, Beverly Hills-Londres- Nueva Delhi, Sage, pp.105-130. 
REDES- Revista hispana para el análisis de redes sociales

Vol. 21, \#4 Diciembre 2011

http://revista-redes.rediris.es

Granovetter, M.S. (1985), "Economic Action and Social Structure: The Problem of Embeddedness", Americain Journal of Sociology, vol.91-3, pp. 481-510.

Guerrero Elecalde, R. (2012), Las elites vascas y navarras en el gobierno de la Monarquía borbónica: Redes sociales, carreras y hegemonía en el siglo XVIII (17001746), Bilbao, Universidad del País Vasco.

Hausberger, B. (2003), "La red social del alavés Tomás Ruiz de Apodaca, comerciante en Cádiz", en A. Acosta Rodríguez, A. González Rodríguez y E. Vila Vilar (coords.), La Casa de Contratación y la navegación entre España y las Indias, Sevilla, Universidad de Sevilla, CSIC, Fundación El Monte, pp. 885-909

Imízcoz, J.M. (1998), "Communauté, réseau social, élites. L'armature sociale de I'Ancien Régime", en J.L Castellano, J.P. Dedieu, Réseaux, familles et pouvoirs dans le monde ibérique à la fin de l'Ancien Régime, Paris, CNRS, pp. 31-66.

Imízcoz, J.M. (2001), "Patronos y mediadores. Redes familiares en la Monarquía y patronazgo en la aldea: la hegemonía de las elites baztanesas en el siglo XVIII", en Imízcoz J.M. (dir.), Redes familiares y patronazgo. Aproximación al entramado social del País Vasco y Navarra en el Antiguo Régimen (siglos XV-XIX), Bilbao, Universidad del País Vasco, pp.225-261.

Imízcoz, J.M. (2003), "Parentesco, amistad y patronazgo. La economía de las relaciones familiares en la hora navarra del siglo XVIII", en C. Fernández y A.Moreno (ed.), Familia y cambio social en Navarra y País Vasco. Siglos XIII al XX, Pamplona, Instituto de Ciencias para la familia, pp.165-216.

Imízcoz, J.M. (2004), "Actores, redes, procesos: reflexiones para una historia más global", Revista da Facultade de Letras História, Porto, III Série, vol.5, pp.115-140.

Imízcoz, J.M. (2007), "Elites administrativas, redes cortesanas y captación de recursos en la construcción social del Estado moderno", Trocadero (19), pp. 11-30.

Imízcoz, J.M. (2008), "Las élites vasco-navarras y la monarquía hispánica: construcciones sociales, políticas y culturales en la Edad Moderna", Cuadernos de Historia Moderna, vol.33, pp.89-119.

Imízcoz, J.M. (2009), "Las redes sociales de las élites. Conceptos, fuentes y aplicaciones", en E. Soria Mesa, J.J. Bravo Caro y J.M. Delgado Barrado (eds.), Las élites en la época moderna: La Monarquía española, Universidad de Córdoba, t.I, Nuevas perspectivas, pp. 77-111.

Imízcoz, J.M. (2010a), "El capital relacional. Relaciones privilegiadas y redes de influencia en el Estado español del siglo XVIII", en J.M. Imízcoz y O. Oliveri (eds.), Economía doméstica y redes sociales en el Antiguo Régimen, Madrid, Silex, pp. 227-281.

Imízcoz, J.M. (2010b), "Solidaridades y conflictos. Las relaciones personales en la construcción de economías compartidas y dinámicas duraderas", en J.M. Imízcoz y O. Oliveri (eds.), Economía doméstica y redes sociales en el Antiguo Régimen, Madrid, Silex, pp. 283-334.

Imízcoz, J.M. (2010c), "Réseaux et pratiques familiales dans la reproduction des élites de I'Etat espagnol au XVIIIe siècle", en Colloque International Réseaux, familles et génerations dans l'Europe moderne, Rouen, 25-26 novembre 2010.

Imízcoz, J.M. (2011a), "Las redes de la monarquía: familia y redes sociales en la construcción de España", en F.Chacón y J. Bestard (dirs.), Familias. Historia de la sociedad española (de final de la Edad Media a nuestros días), Madrid, Cátedra, pp. 393-444. 
REDES- Revista hispana para el análisis de redes sociales

Vol. 21, \#4 Diciembre 2011

http://revista-redes.rediris.es

Imízcoz, J.M. (2011b), "Actores y redes sociales en Historia", en D. Carvajal de la Vega, J. Añíbarro Rodríguez, I. Vítores Casado (Coords.), Redes sociales y económicas en el mundo bajomedieval, Valladolid, Castilla Ediciones, pp. 17-29

Imízcoz, J.M.; Caula, E. (2004), "Un mundo de sombras por iluminar. Lenguajes y discursos de la correspondencia epistolar", en La correspondencia: instrumento privilegiado de la historia sociocultural de la Modernidad Temprana (s. XVI al XVIII) mesa temática de las IV Jornadas de Historia Moderna y Contemporánea, Resistencia, Argentina, inédito.

Imízcoz, J.M.; García del Ser, M.V. (2008), "El alto clero vasco y navarro en la monarquía hispánica del siglo XVIII: bases familiares, economía del parentesco y patronazgo", en R. Aguirre y L. Enríquez (Coords.), La Iglesia hispanoamericana, de la colonia a la república, México, pp.144-147.

Imízcoz, J.M.; Guerrero, R. (2004), "Familias en la Monarquía. La política familiar de las élites vasco-navarras en el Imperio de los Borbones", en J.M. Imízcoz (dir.), Casa, familia y sociedad. País Vasco, España y América, siglos XV-XIX, Bilbao, Universidad del País Vasco, 177-238.

Imízcoz J.M.; Guerrero R. (2011), "Negocios y clientelismo político. Los empresarios norteños en la economía de la monarquía borbónica", en J. Ocampo Suárez-Valdés (ed.), Empresa y empresarios en el norte de España (siglo XVIII), Oviedo, Trea, pp. 331-362.

Imízcoz, J.M., Oliveri, O. (eds.) (2010), Economía doméstica y redes sociales en el Antiguo Régimen, Madrid, Silex.

Lamikiz, X. (2007), "Patrones de comercio y flujo de información comercial entre España y América durante el siglo XVIII, en Revista de Historia económica, Journal of Iberian and Latin American Economic History, Año XXV, no 2, pp. 233-260

Lemercier, C. (2005a), «Analyse de réseaux et histoire de la famille: une rencontre encore à venir ? », Annales de Démographie Historique, n01, pp. 7-31

Lemercier, C. (2005b), "Analyse de réseaux et histoire", Revue d'Histoire Moderne et Contemporaine, 52-2, avril-juin 2005, pp.88-112.

Levi, G. (1990), La herencia inmaterial, Madrid, Nerea.

Lorenzo Cadarso, P.L. (2001), "La correspondencia administrativa en el Estado absoluto castellano (s. XVI-XVII)", Tiempos Modernos: Revista Electrónica de Historia Moderna, vol.2, N05.

Márquez Macías, R. (2004-2005), "Cartas de amor y silencios. La correspondencia privada entre Buenos Aires y España en el siglo XVIII", Fundación, n07, pp. 229242.

Márquez Macías, R. (1988), "La emigración a Indias a través de la correspondencia de los emigrantes, 1765-1824", Rábida, n04, pp. 45-54

McCarty, C. (2010), "La estructura en las redes personales", Redes-Revista hispana para el análisis de redes sociales, vol. 19 (http://revista-redes.rediris.es)

Mestre Sanchís, A. (1999-2000), "La carta, fuente de conocimiento histórico", Revista de Historia Moderna. Anales de la Universidad de Alicante, 18, pp. 13-26

Molina, J.L. (2001), El análisis de redes sociales. Una introducción, Barcelona, ed. Bellaterra.

Molina, J.L.; Ruiz, A.A.; Teves, L. (2005), "Localizando geográficamente las redes personales", Redes-Revista hispana para el análisis de redes sociales, vol. 8 (http://revista-redes.rediris.es) 
REDES- Revista hispana para el análisis de redes sociales

Vol. 21, \#4 Diciembre 2011

http://revista-redes.rediris.es

Moutoukias, Z. (1995), "Narración y análisis en la observación de vínculos y dinámicas sociales: el concepto de red personal en la Historia social y económica", en $\mathrm{M}$. Bejerg y $\mathrm{H}$. Otero (Comp.). Inmigración y redes sociales en la Argentina moderna, Tandil, IEHS-CEMLA, p. 228.

Moutoukias, Z. (2000), "Familias patriarcales o redes sociales: balance de una imagen de la estratificación social", Anuario del IEHS, 15, pp.133-151

Moutoukias, Z. (2002), "Lazos débiles/lazos fuertes y la organización espacial de los negocios en Hispanoamérica colonial (segunda mitad del siglo XVIII)", en M. Bertrand (coord.), Configuraciones y redes de poder. Un análisis de las relaciones sociales en América Latina, Caracas, editorial Tropykos, pp. 15-26.

Moutoukias, Z. (2003a), "Réseaux egocentrés, ressources spécifiques et médiations politiques » en Les économies de I'ancien régime en Amérique espagnole: commerce, réseaux sociaux et dynamiques, Mémoire d'habilitation, Paris, EHESS, vol I, cap.2 (ejemplar mecanografiado)

Moutoukias, Z. (2003b), "Réseaux sociaux/ réseaux egocentrés », en Les économies de l'ancien régime en Amérique espagnole : commerce, réseaux sociaux et dynamiques, Mémoire d'habilitation, Paris, EHESS, vol I, cap.5 (ejemplar mecanografiado).

Moutoukias, Z. (2003c), « Réseaux de négociants ou réseaux egocentrés: une approche méthodologique », en P.-Y. Beaurepaire y D. Taurisson (eds.), Les Egodocuments à l'heure de l'électronique. Nouvelles approches des espaces relationnels, Université Paul Valéry- Montpellier III, pp. 447-468.

Pourchasse, P.; Beaurepaire, P.-Y. (ed.) (2010), Les circulations internationales en Europe, 1680-1780, Rennes, Presses Universitaires de Rennes.

Requena Santos, F., (ed.) (2003), Análisis de redes sociales. Orígenes, teorías y aplicaciones, Madrid, CIS, ed. Siglo XXI.

Ruiz León, A.A.; Gil-Mendieta, J. (2007), "Redes variables en el tiempo: visualización con Pajek", Redes-Revista hispana para el análisis de redes sociales, vol. 12 (http://revista-redes.rediris.es)

Sáez, C.; Castillo Gómez, A. (ed.) (2002), La correspondencia en la historia. Modelos y prácticas de escritura epistolar. Actas del VI Congreso Internacional de historia de la Cultura escrita, vol. I, Calambur.

Sánchez Rubio, R.; Testón Núñez, I. (1999), El hilo que une. Las relaciones epistolares en el Viejo Mundo y el Nuevo Mundo (ss. XVI-XVIII), Universidad de Extremadura, Cáceres-Mérida.

Testón Núñez, I.; Sánchez Rubio, R. (2008), "De todo he estado ignorante por no haber visto letra de vuesa merced". La correspondencia epistolar como vehículo de comunicación en la sociedad moderna", en J.L. Castellano y M.L. López-Guadalupe Muñoz (coord.), Homenaje a Antonio Domínguez Ortiz, vol.2, pp-771-778

Urkia, J.M. ; Risco, A. (2005), "La carta como fuente y como texto. La correspondencia societaria en el siglo XVIII: la Real Sociedad Bascongada de los Amigos del País", RSBAP.

Usunáriz Garayoa, J.M. (1992), Una visión de la América del siglo XVIII: correspondencia de emigrantes guipuzcoanos y navarros, Madrid, Mapfre.

Wasserman, S.; Faust, K. (1994), Social Network Analysis, New York, Cambridge University Press. 